\title{
Asymmetric Syntheses of Phosphatidylinositol-3-Phosphates with Saturated and Unsaturated Side Chains through Catalytic Asymmetric Phosphorylation
}

\author{
Bianca R. Sculimbrene, Yingju Xu and Scott J. Miller \\ Department of Chemistry, Merkert Chemistry Center, Boston College, Chestnut Hill, \\ Massachusetts 02467-3860, USA
}

\section{Supporting Information}

\section{General Procedures.}

Proton NMR spectra were recorded on Varian 400 or 300 spectrometers. Proton chemical shifts are reported in ppm ( $\square$ relative to internal tetramethylsilane (TMS, $\square 0.0$ ) or with the solvent reference relative to TMS employed as the internal standard $\left(\mathrm{CDCl}_{3}, \square 7.26 \mathrm{ppm} ; \mathrm{d}_{6}\right.$ DMSO, $\square 2.50 ; \mathrm{C}_{6} \mathrm{D}_{6}, \square 7.16 \mathrm{ppm} ; \mathrm{D}_{2} \mathrm{O}, \square 4.79$ ). Data are reported as follows: chemical shift (multiplicity [singlet (s), doublet (d), triplet (t), quartet (q), and multiplet (m)], coupling constants [Hz], integration). Carbon NMR spectra were recorded on Varian 400 (100 MHz) or $300(75 \mathrm{MHz})$ spectrometers with complete proton decoupling. Carbon chemical shifts are reported in ppm ( $\square$ ) relative to TMS with the respective solvent resonance as the internal standard $\left(\mathrm{CDCl}_{3}, \mathrm{777.0)}\right.$. Phosphorous NMR spectra were recorded on Varian 400 (162 $\mathrm{MHz})$ spectrometer with complete proton decoupling. Phosphorous chemical shifts are reported in ppm ( $\square$ relative to a $85 \% \mathrm{H}_{3} \mathrm{PO}_{4}$ external standard $\left(\mathrm{H}_{3} \mathrm{PO}_{4}, 0.0\right)$. NMR data were collected at $25{ }^{\circ} \mathrm{C}$, unless otherwise indicated. Infrared spectra were obtained on a PerkinElmer Spectrum 1000 spectrometer. Analytical thin-layer chromatography (TLC) was performed using Silica Gel 60 F254 precoated plates ( $0.25 \mathrm{~mm}$ thickness). TLC $\mathrm{R}_{f}$ values are reported. Visualization was accomplished by irradiation with a UV lamp and/or staining with $\mathrm{KMnO}_{4}$ or cerium ammonium molybdenate (CAM) solutions. Flash column 
chromatography was performed using Silica Gel 60A (32-63 $\square \mathrm{m}) .{ }^{1}$ Optical rotations were recorded on a Rudolf Research Analytical Autopol IV Automatic polarimeter at the sodium D line (path length $50 \mathrm{~mm}$ ). Elemental analyses were performed by Robertson Microlit (Madison, NJ). High resolution mass spectra were obtained at the Mass Spectrometry Facility at Boston College (Chestnut Hill, MA). The method of ionization is given in parentheses.

Analytical and preparative reverse phase and normal phase HPLC were performed on a Rainin SD-200 chromatograph equipped with a single wavelength UV detector (214 nm or $254 \mathrm{~nm}$ ). Analytical normal phase HPLC was performed on a Hewlett-Packard 1100 Series chromatograph equipped with a diode array detector (214 nm and $254 \mathrm{~nm})$.

All reactions were carried out under an argon or nitrogen atmosphere employing oven- and flame-dried glassware. All solvents were distilled from appropriate drying agents prior to use. Diphenyl chlorophosphate was distilled prior to use and stored in a Schlenk tube for no more than 2 weeks. 2,4,6-Tri- $O$-benzyl-myo-inositol was prepared according to the method of Billington. ${ }^{2}$ 2,4,6-Tri-O-para-methoxybenzyl-myo-inositol (10) was prepared from a modified procedure (the deprotection of the orthoester was conducted at ambient temperature for $8 \mathrm{hrs})^{3} .5$ and $\boldsymbol{e n t - 5}$ were synthesized from peptide catalyzed phosphorylation. ${ }^{4}$

\section{Synthesis of Phosphatidyl Inositol with Phenyl Phosphates}

\section{Synthesis of phosphatidyl inositol 7}

Diisopropylethylamine $(1.1 \mathrm{~mL}, 6.2 \mathrm{mmol})$ was dissolved in $32 \mathrm{~mL}$ of THF and cooled to $-25{ }^{\circ} \mathrm{C}$ in a dry ice/acetonitrile bath. Phenylphosphorodichloridite $(0.320 \mathrm{~mL}, 2.20 \mathrm{mmol})$

\footnotetext{
${ }^{1}$ Still, W.C.; Kahn, M.; Mitra, J. J. Org. Chem. 1978, 43, 2923.

${ }^{2}$ Billington, D.C; Baker, R.; Kulagowski, J.J.; Mawer, I.M.; Vacca, J.P.; deSolms, S.J.; Huff, J.R. J. Chem. Soc. Perkin Trans. I 1989, 1423.

${ }^{3}$ Lampe, D.; Lui, C.; Potter, B.V.L. J. Med. Chem. 1994, 37, 907-912.

${ }^{4}$ Sculimbrene, B.R.; Morgan, A.J.; Miller, S.J. J. Am. Chem. Soc. 2002, 124, 11653-11656.
} 
was added followed by (R)-1,2-dioctylglycerol ${ }^{5}(0.760 \mathrm{~g}, 2.20 \mathrm{mmol})$ in $20 \mathrm{~mL}$ of THF. The reaction was stirred for $30 \mathrm{~min}$ and then 1- $O$-diphenylphosphate-2,4,6- $O$-tribenzyl-myoinositol (5) (1.0 g, $1.5 \mathrm{mmol})$ was delivered in $6 \mathrm{~mL}$ of THF. The reaction was stirred for an additional $20 \mathrm{~min}$ and then warmed to ambient temperature and stirred for $12 \mathrm{hrs}$. The reaction was then concentrated under reduced pressure and the resulting residue dissolved in ethyl acetate and filtered through a pad of celite. The celite was washed with $50 \mathrm{~mL}$ of ethyl acetate and the filtrate was concentrated under reduced pressure. The resulting residue was dissolved in $5 \mathrm{~mL}$ of $\mathrm{CH}_{2} \mathrm{Cl}_{2}$ and cooled to $0{ }^{\circ} \mathrm{C}$. $30 \% \mathrm{H}_{2} \mathrm{O}_{2} / \mathrm{H}_{2} \mathrm{O}(3.0 \mathrm{~mL})$ was added and the reaction stirred for $30 \mathrm{~min}$. The solution was quenched with a saturated $\mathrm{Na}_{2} \mathrm{SO}_{3}$ solution and extracted with $2 \times 30 \mathrm{~mL}$ of $\mathrm{CH}_{2} \mathrm{Cl}_{2}$. The combined organic layers were dried with $\mathrm{Na}_{2} \mathrm{SO}_{4}$ and concentrated under reduced pressure. The crude material was purified by flash chromatography with a gradient of hexanes to $35 \%$ ethyl acetate/hexanes to yield $0.540 \mathrm{~g}$ (31\% yield) of 7 as a 1:1 mixture of diastereomers at Phosphorus.

\section{Phosphatidyl inositol 7}

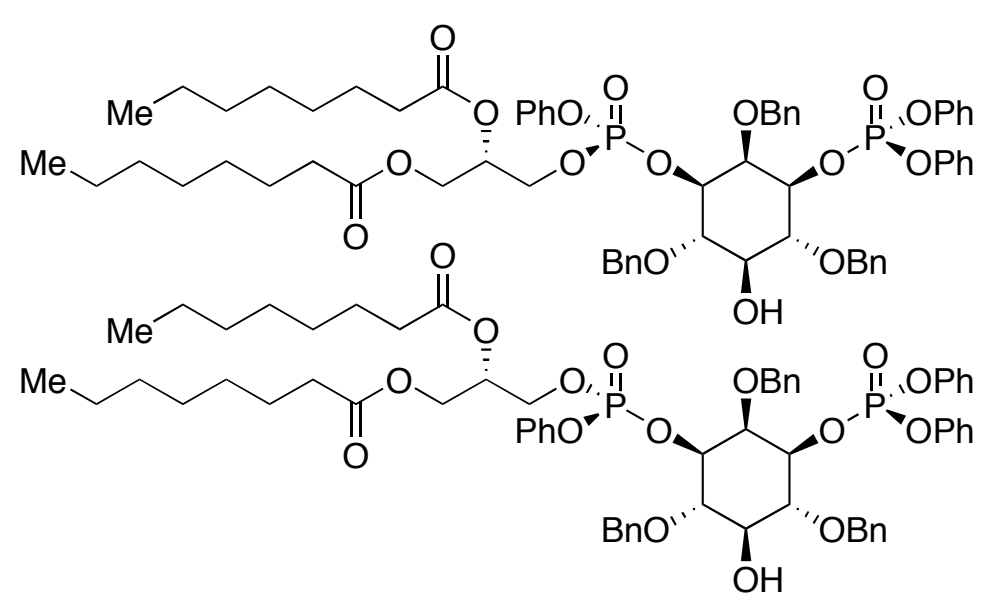

${ }^{1} \mathbf{H}$ NMR $\left(\mathrm{CDCl}_{3}, 400 \mathrm{MHz}\right)$ $7.38-7.11(\mathrm{~m}, 25 \mathrm{H}), 5.06(\mathrm{~m}$, $1 \mathrm{H}), 4.82-4.58(\mathrm{~m}, 6 \mathrm{H}), 4.50$ $4.38(\mathrm{~m}, 3 \mathrm{H}), 4.21-3.87(\mathrm{~m}, 6 \mathrm{H})$, $3.60(\mathrm{~m}, 1 \mathrm{H}), 2.18(\mathrm{~m}, 4 \mathrm{H}), 1.53$ $(\mathrm{m}, 4 \mathrm{H}), 1.24(\mathrm{~m}, 16), 0.86(\mathrm{~m}$, $6 \mathrm{H}) ;{ }^{13} \mathrm{C}$ NMR $\left(\mathrm{CDCl}_{3}, 100 \mathrm{MHz}\right)$ $172.7,172.4,172.3,150.3$, 150.2, 138.1, 138.0, 137.9, 129.6, 129.6, 128.2, 128.2, 128.1, 128.0, 127.9, 127.7, 127.6, 127.5, 127.5, 127.4, 127.3, 127.1, $126.9,125.3,125.2,125.1,119.9,119.9,119.8,119.8,119.7,79.3,79.3,79.2,78.9,78.8$, 78.6, 78.5, 78.3, 78.2, 75.6, 75.4, 75.3, 75.1, 74.8, 74.4, 69.2, 69.1, 69.0, 66.4, 66.1, 61.3, 34.0, 34.0, 31.7, 29.1, 29.0, 28.9, 24.8, 24.8, 22.6, 14.1; ${ }^{13} \mathbf{P} \mathbf{N M R}\left(\mathrm{CDCl}_{3}, 162 \mathrm{MHz}\right) \square-5.4$, -6.6, -11.4, -11.7; IR (film, $\mathrm{cm}^{-1}$ ) 3437, 3064, 2928, 2856, 1742, 1591, 1490, 1361, 1282;

\footnotetext{
${ }^{5}$ Martin, S.F.; Josey, J.A.; Wong, Y.L.; Dean, D.W. J. Org. Chem. 1994, 59, 4805-4820.
} 
TLC $\mathbf{R}_{f} 0.43$ (35\% ethyl acetate/hexanes); Exact mass calcd for $\left[\mathrm{C}_{64} \mathrm{H}_{78} \mathrm{O}_{16} \mathrm{P}_{2}+\mathrm{Na}\right]+$ requires $m / z$ 1187.4663. Found $1187.4668(\mathrm{ESI}+)$.

\section{Synthesis of Phosphatidyl Inositols with Benzyl Phosphates}

\section{Synthesis of 3,5-O-bis(t-Butyldimethylsilyl-1- $O$-diphenylphosphate-2,4,6- $O$-tribenzyl-D-} myo-Inositol

$5(1.0 \mathrm{~g}, 1.5 \mathrm{mmol})$ was dissolved in $13 \mathrm{~mL}$ of DMF. tert-Butyldimethylsilylchloride $(1.1 \mathrm{~g}$, $7.3 \mathrm{mmol})$ and imidazole $(1.0 \mathrm{~g}, 15 \mathrm{mmol})$ were added to the reaction, which was then heated to $55{ }^{\circ} \mathrm{C}$ for $48 \mathrm{hr}$. The reaction was then cooled to $\mathrm{RT}$ and quenched with $20 \mathrm{~mL}$ of saturated $\mathrm{NH}_{4} \mathrm{Cl}$. The mixture was extracted with $2 \mathrm{X} 40 \mathrm{~mL}$ of diethyl ether. The combined organic layers were dried with $\mathrm{Na}_{2} \mathrm{SO}_{4}$ and concentrated. The crude product was purified by silica gel chromatography eluting with a slow gradient of hexanes to $7.5 \%$ ethyl acetate / hexanes to yield $1.2 \mathrm{~g}$ (89\% yield) as an oily solid.

\section{3,5-O-bis( $t$-Butyldimethylsilyl-1- $O$-diphenylphosphate-2,4,6-O-tribenzyl-D-myo-Inositol}

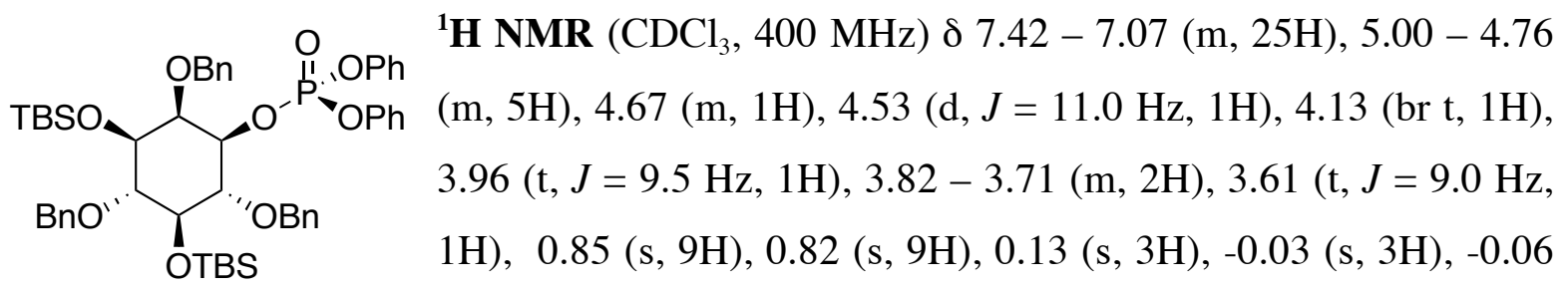

(s, 3H), -0.09 (s, 3H); ${ }^{13} \mathbf{C} \mathbf{N M R}\left(\mathrm{CDCl}_{3}, 100 \mathrm{MHz}\right) \square$ 150.3, 150.2, 138.9, 138.8, 138.3, $129.5,129.4,128.0,127.7,127.5,127.2,127.1,126.9,126.6,126.3,125.7,125.1,124.9$, $119.9,119.8,119.6,119.5,81.5,80.7,80.1,80.0,80.0,75.4,75.0,75.0,74.9,73.9$, 26.0, 25.9, -3.9, -4.1, -4.8; ${ }^{13} \mathbf{P}$ NMR $\left(\mathrm{CDCl}_{3}, 162 \mathrm{MHz}\right) \square-11.1$; IR (film, $\left.\mathrm{cm}^{-1}\right)$ 3068, 3030, 2936, 2854, 1596, 1495, 1300; TLC $\mathbf{R}_{f} 0.50$ (20\% ethyl acetate/hexanes); [ $]_{\mathrm{D}}=-26.2(1.0$, $\mathrm{CHCl}_{3}$, at $>98 \%$ ee); Exact mass calcd for $\left[\mathrm{C}_{51} \mathrm{H}_{67} \mathrm{O}_{9} \mathrm{PSi}_{2}+\mathrm{Na}\right]+$ requires $\mathrm{m} / z$ 933.3953. Found 933.3959 (ESI+). 
1,5-O-bis(t-Butyldimethylsilyl-3- $O$-diphenylphosphate-2,4,6- $O$-tribenzyl-D-myo-Inositol

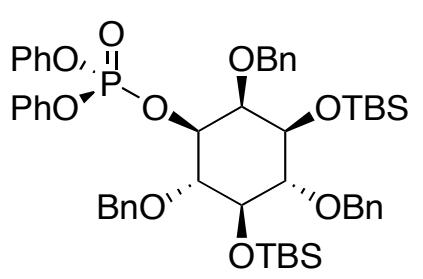

Synthesis and spectral data identical to 3,5-O-bis $(t$ butyldimethylsilyl-1-O-diphenylphosphate-2,4,6-O-tribenzyl-Dmyo-Inositol $[\square]_{\mathrm{D}}=+25.0\left(1.0, \mathrm{CHCl}_{3}\right.$, at $>98 \%$ ee $)$

\section{Synthesis of 3,5-O-bis(t-Butyldimethylsilyl)-1- $O$-dibenzylphosphate-2,4,6- $O$-tribenzyl-D- myo-inositol}

Benzyl alcohol $(0.430 \mathrm{~mL}, 4.16 \mathrm{mmol})$ was dissolved in $20 \mathrm{~mL}$ of THF and sodium hydride $(0.100 \mathrm{~g}, 4.17 \mathrm{mmol})$ was added portionwise. 3,5-O-bis( $t$-Butyldimethylsilyl-1- $O$ diphenylphosphate-2,4,6- $O$-tribenzyl-D-myo-Inositol $(1.30 \mathrm{~g}, 1.42 \mathrm{mmol})$ was dissolved in $30 \mathrm{~mL}$ of THF and added to the reaction over $5 \mathrm{~min}$ via canulation. After $1 \mathrm{~h}$, the reaction was neutralized with $0.5 \mathrm{M}$ citric acid and the THF was concentrated under reduced pressure. The resulting slurry was extracted with $2 \times 100 \mathrm{~mL}$ of ethyl acetate and $75 \mathrm{~mL}$ of brine. The combined organic layers were dried with $\mathrm{Na}_{2} \mathrm{SO}_{4}$ and concentrated under reduced pressure. The crude product was purified by silica gel chromatography eluting with a slow gradient of hexanes to $15 \%$ ethyl acetate / hexanes to yield $1.10 \mathrm{~g}$ (84\% yield) of an oily solid.

3,5-O-bis( $t$-Butyldimethylsilyl)-1- $O$-dibenzylphosphate-2,4,6-O-tribenzyl-D-myo-inositol

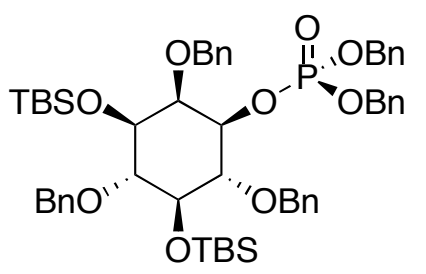

${ }^{1} \mathbf{H}$ NMR $\left(\mathrm{CDCl}_{3}, 400 \mathrm{MHz}\right) \square 7.40-7.12(\mathrm{~m}, 25 \mathrm{H}), 4.96-4.87$ $(\mathrm{m}, 4 \mathrm{H}), 4.82-4.67(\mathrm{~m}, 4 \mathrm{H}), 4.28(\mathrm{~m}, 1 \mathrm{H}), 4.13(\mathrm{dd}, J=2.2 \mathrm{~Hz}$, $2.6 \mathrm{~Hz}, 1 \mathrm{H}), 3.87(\mathrm{t}, J=9.5,1 \mathrm{H}), 3.72(\mathrm{dd}, J=9.2 \mathrm{~Hz}, 9.5 \mathrm{~Hz}$, $1 \mathrm{H}), 3.60(\mathrm{dd}, J=2.2 \mathrm{~Hz}, 9.5 \mathrm{~Hz}, 1 \mathrm{H}), 3.50(\mathrm{t}, J=8.8 \mathrm{~Hz}, 1 \mathrm{H})$, 0.79 (s, 9H), 0.78 (s, 9H), 0.03 (s, 3H), -0.05 (s, 3H), -0.06 (s, 3H), $-0.13(\mathrm{~s}, 3 \mathrm{H}) ;{ }^{13} \mathrm{C}$ NMR $\left(\mathrm{CDCl}_{3}, 100 \mathrm{MHz}\right) \square 139.0,139.0,138.5,135.6,135.5,129.3,128.3$, 128.3, 123.2, 128.0, 127.8, 127.7, 127.5, 127.5, 127.2, 127.1 127.0, 126.8, 126.2, 125.9, $119.5,115.4,81.6,80.6,80.3,80.2,78.9,78.8,75.5,75.2,75.0,74.9,73.8,69.3,69.2,69.1$, 69.0, 26.0, 25.9, 18.1, 18.0, -3.8, -3.8, -4.2, -4.8; ${ }^{31} \mathbf{P}$ NMR $\left(\mathrm{CDCl}_{3}, 162 \mathrm{MHz}\right) \square-0.3$; IR $\left(\right.$ film, $\left.\mathrm{cm}^{-1}\right) 3024,2924,2848,1495,1463,1381,1255$; TLC $\mathbf{R}_{f} 0.37$ (20\% ethyl 
acetate/hexanes); $[\square]_{\mathrm{D}}=-19.0\left(1.0, \mathrm{CHCl}_{3}\right.$, at $>98 \%$ ee $)$; Exact mass calcd for $\left[\mathrm{C}_{53} \mathrm{H}_{71} \mathrm{O}_{9} \mathrm{Si}_{2} \mathrm{P}\right.$ $+\mathrm{Na}$ ] requires $\mathrm{m} / \mathrm{z}$ 961.4272. Found 961.4257 (ESI+).

\section{1,5-O-bis(t-Butyldimethylsilyl)-3-O-dibenzylphosphate-2,4,6-O-tribenzyl-D-myo-inositol}

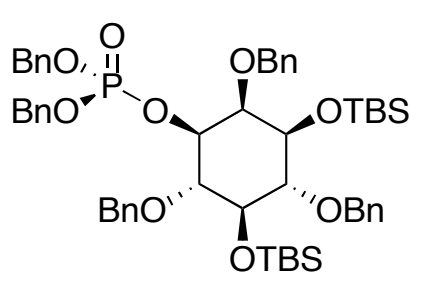

Synthesis and spectral data identical to $1,5-O$-bis $(t-$ butyldimethylsilyl)-3-O-dibenzylphosphate-2,4,6- $O$-tribenzyl-Dmyo-inositol [ []$_{\mathrm{D}}=+16.6\left(1.0, \mathrm{CHCl}_{3}\right.$, at $>98 \%$ ee $)$

\section{Synthesis of 1-Dibenzylphosphate-2,4,6-tri- $O$-benzyl-D-myo-Inositol (8).}

3,5-O-bis(t-Butyldimethylsilyl)-1-O-dibenzylphosphate-2,4,6-O-tribenzyl-D-myo-inositol $(1.05 \mathrm{~g}, 1.12 \mathrm{mmol})$ was dissolved in $20 \mathrm{~mL}$ of THF and added to a Teflon container. HFpyridine $(3.0 \mathrm{~mL})$ was added. After $36 \mathrm{hrs}$ the reaction was filtered through a silica gel plug and washed with $40 \mathrm{~mL}$ of THF. The filtrate was concentrated under reduced pressure. The crude material was purified using silica gel flash chromatography eluting with 50\% ethyl acetate/hexanes to yield 8 ( $0.670 \mathrm{~g}, 86 \%$ yield), as a viscous oil.

\section{1-O-Dibenzylphosphate-2,4,6-tri-O-benzyl-D-myo-Inositol (8)}

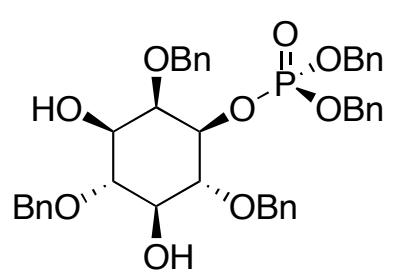

${ }^{1} \mathbf{H}$ NMR $\left(\mathrm{CDCl}_{3}, 400 \mathrm{MHz}\right) \square 7.41-7.26(\mathrm{~m}, 25 \mathrm{H}), 5.04(\mathrm{~m}, 4 \mathrm{H})$, $4.93-4.76(\mathrm{~m}, 6 \mathrm{H}), 4.33(\mathrm{~m}, 1 \mathrm{H}), 4.23(\mathrm{t}, J=2.4,1 \mathrm{H}), 3.94(\mathrm{t}, J=$ 9.3, 1H), $3.71(\mathrm{t}, J=9.5,1 \mathrm{H}), 3.55(\mathrm{~m}, 2 \mathrm{H}) ;{ }^{13} \mathbf{C} \mathbf{~ N M R}\left(\mathrm{CDCl}_{3}, 100\right.$ MHz) $\square$ 138.4, 138.1, 128.4, 128.4, 128.3, 128.2, 127.9, 127.8, 127.6, 127.5, 127.4, 81.2, 80.1, 80.0, 78.9, 78.6, 78.6, 75.4, 75.2, 75.0, 74.7, 71.8, 69.6, 69.5, 69.4, 69.4; ${ }^{31} \mathbf{P}$ NMR $\left(\mathrm{CDCl}_{3}, 162 \mathrm{MHz}\right) \square-0.3$; IR (film, $\left.\mathrm{cm}^{-1}\right)$; TLC $\mathbf{R}_{f} 0.35$ (50\% ethyl acetate/hexanes); []$_{D}=+2.1\left(6.5, \mathrm{CHCl}_{3}\right.$, at $>98 \%$ ee $)$; Exact mass calcd for $\left[\mathrm{C}_{41} \mathrm{H}_{43} \mathrm{O}_{9} \mathrm{P}+\right.$ $\mathrm{Na}]+$ requires $\mathrm{m} / \mathrm{z}$ 733.2542. Found 733.2540 (ESI+); Assay of enantiomeric purity. Enantiomers of $\mathbf{8}$ were separated utilizing a Chiracel OD column (Alltech), eluting with 20\% ethanol/hexanes at a flow rate of $0.5 \mathrm{~mL} / \mathrm{min}$. Retention times $\mathrm{R}_{\text {minor }}=15.5 \mathrm{~min}, \mathrm{R}_{\text {major }}=19.5$ $\min$. 


\section{3-O-Dibenzylphosphate-2,4,6-tri-O-benzyl-D-myo-Inositol}

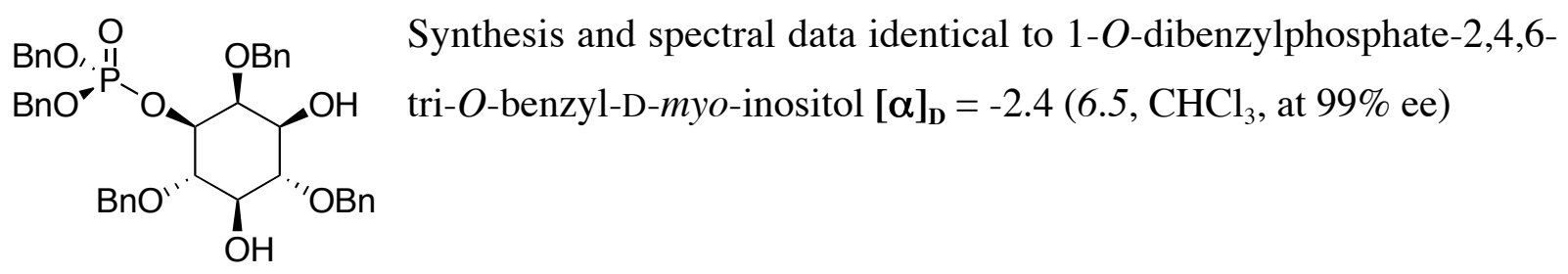

\section{Synthesis of Protected Phosphatidyl Inositol 9}

$8(0.120 \mathrm{~g}, 0.169 \mathrm{mmol})$ was dissolved in $\mathrm{CH}_{2} \mathrm{Cl}_{2}(0.5 \mathrm{~mL})$ and a solution of tetrazole (3.0 $\mathrm{mL}, 0.91 \mathrm{mmol}, 3 \% \mathrm{w} / \mathrm{v}$ solution in acetonitrile) was added. Glycerol phosphoamidite $\mathbf{6} \mathbf{b}^{6}$ $(0.140 \mathrm{~g}, 0.241 \mathrm{mmol})$ was dissolved in $3 \mathrm{~mL}$ of $\mathrm{CH}_{2} \mathrm{Cl}_{2}$ and added to the reaction via canulation over $5 \mathrm{~min}$. After $1 \mathrm{hr}$ the reaction was cooled to $0{ }^{\circ} \mathrm{C}$ and $30 \% \mathrm{H}_{2} \mathrm{O}_{2} / \mathrm{H}_{2} \mathrm{O}(2 \mathrm{~mL})$ was added. After $1 \mathrm{hr}$ the reaction was quenched with a saturated $\mathrm{Na}_{2} \mathrm{SO}_{3}$ solution and washed with $3 \times 25 \mathrm{~mL} \mathrm{CH}_{2} \mathrm{Cl}_{2}$. The combined organic layers were dried with $\mathrm{Na}_{2} \mathrm{SO}_{4}$ and concentrated under reduced pressure. The crude material was purified by silica gel flash chromatography with a gradient of $25 \%$ ethyl acetate/hexanes to $100 \%$ ethyl acetate. This material was further purified by normal phase HPLC. Preparative HPLC was performed using a normal phase YMC-pack PVA-Sil NP column, eluting with a gradient of hexanes to $6.5 \%$ 2-propanol/hexanes over $40 \mathrm{~min}$, at a flow rate of $10 \mathrm{~mL} / \mathrm{min} .65 \mathrm{mg}$ of 9 was isolated (32\% yield).

\section{Protected Phosphatidyl Inositol 9}

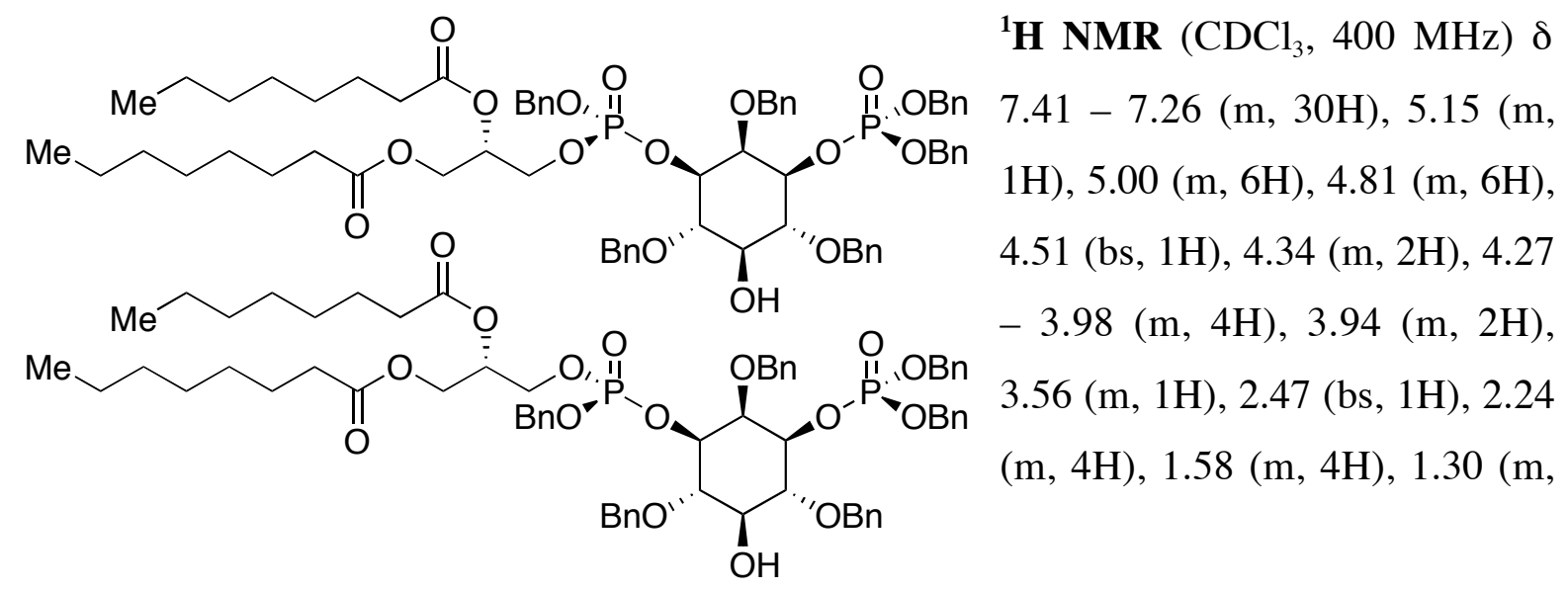

\footnotetext{
${ }^{6}$ Reddy, K.K; Saady, M.; Falck, J.R. J. Org. Chem. 1995, 60, 3385-3390.
} 
16H), $0.91(\mathrm{~m}, 6 \mathrm{H}) ;{ }^{13} \mathbf{C}$ NMR $\left(\mathrm{CDCl}_{3}, 100 \mathrm{MHz}\right) \square 172.8,172.8,172.4,172.4,138.3,138.1$, 138.1, 135.5, 135.4, 135.3, 128.4, 128.4, 128.3, 128.2, 128.2, 128.0, 128.0, 127.7, 127.7, 127.7, 127.6, 127.6, 127.5, 127.5, 127.3, 127.3, 127.1, 127.0, 79.5, 79.5, 79.4, 79.3, 79.2, $78.5,78.4,77.8,77.8,77.6,75.7,75.7,75.1,75.0,74.3,69.7,69.7,69.5,69.4,69.3,69.2$, 69.2, 65.7, 65.7, 65.7, 65.5, 65.4, 61.6, 61.5, 34.1, 34.1, 34.0, 31.7, 29.1, 29.0, 28.9, 24.8, 24.8, 24.8, 22.6, 14.1; ${ }^{31} \mathbf{P}$ NMR $\left(\mathrm{CDCl}_{3}, 162 \mathrm{MHz}\right) \square-0.4,-0.5,-0.5,-0.6$; IR (film, $\mathrm{cm}^{-1}$ ) 3402, 3055, 2923, 2848, 1740, 1451, 1381, 1268; TLC $\mathbf{R}_{f} 0.26$ (35\% ethyl acetate/hexanes); $[\square]_{D}=-3.0$ (6.1, Ethanol); Exact mass calcd for $\left[\mathrm{C}_{67} \mathrm{H}_{84} \mathrm{O}_{16} \mathrm{P}_{2}+\mathrm{H}\right]+$ requires $\mathrm{m} / z$ 1207.5313. Found 1207.5317 (ESI+). HPLC retention time. 32.730 and 34.177 employing a normal phase YMC-Pack PVA-Sil NP column, eluting with a gradient of hexanes to 6.5\% 2propanol/hexanes, at a flow rate of $10 \mathrm{~mL} / \mathrm{min}$.

\section{Protected Phosphatidyl Inositol ent-9}

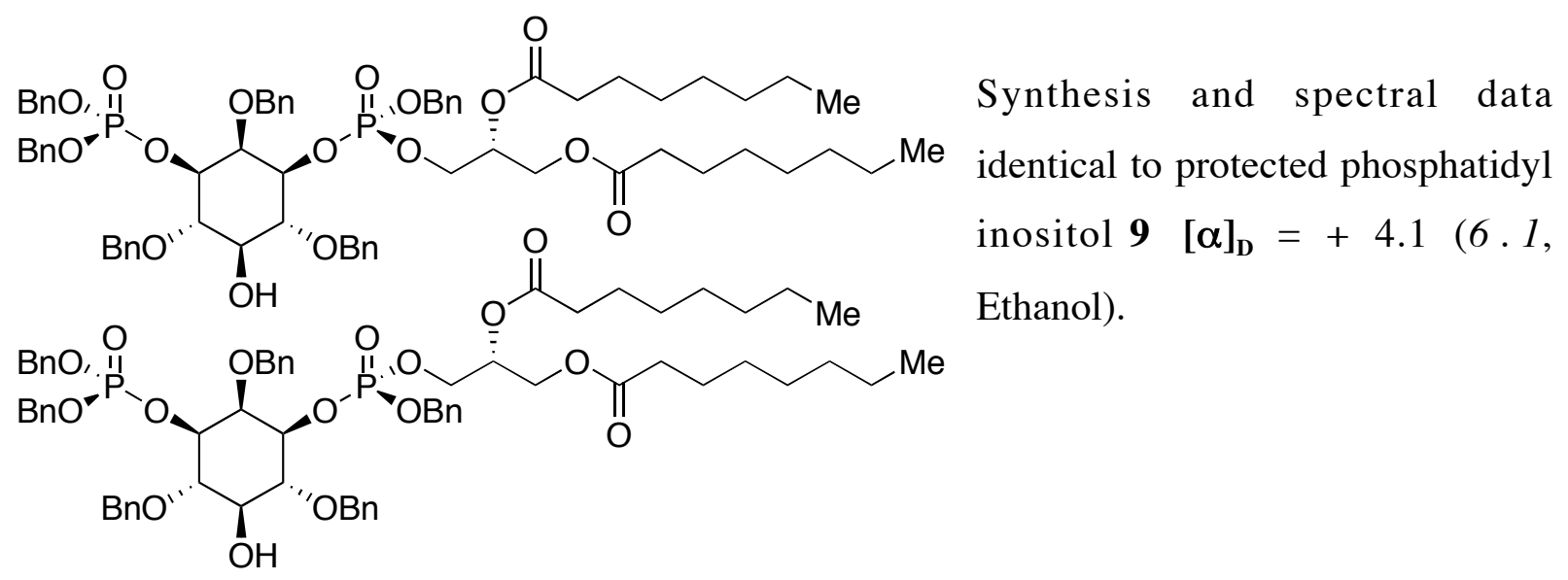

\section{Synthesis of ent-PI3P-(C8)}

$9(0.080 \mathrm{~g}, 0.066 \mathrm{mmol})$ was dissolved in $30 \mathrm{~mL}$ of ethanol and $\mathrm{NaHCO}_{3}(0.016 \mathrm{~g}, 0.18$ mmol, in $5 \mathrm{~mL}$ of $\left.\mathrm{H}_{2} \mathrm{O}\right)$ was added. $10 \%$ palladium on carbon $(0.190 \mathrm{~g})$ was added and the chamber evacuated. The solution was placed under 5 bars of $\mathrm{H}_{2}$ in a Parr hyrdrogenation apparatus. After $16 \mathrm{hrs}$ the reaction was placed under an atmosphere of nitrogen and filtered through celite. The celite was washed with $30 \mathrm{~mL}$ of ethanol and $10 \mathrm{~mL}$ of $\mathrm{H}_{2} \mathrm{O}$. The filtrate was concentrated under reduced pressure (no heating). The resulting solid was dissolved in a 
minimal amount of methanol and run through a Chelex ( $\mathrm{Na}$ form) ion exchange column, eluting with $30 \mathrm{~mL}$ of methanol. The resulting filtrate was concentrated under reduced pressure (no heating) to yield $39 \mathrm{mg}(81 \%$ yield) of $\boldsymbol{e n t}$-PI3P(C8) as a white solid.

ent-PI3P(C8)<smiles>CCCCCCCC(=O)OCC(CO[P+](=O)([O-])O[C@H]1[C@@H](O)[C@H](O)[C@@H](O)[C@H](OP(=O)([O-])[O-])[C@H]1O)OC(=O)CCCCCC</smiles>

${ }^{1} \mathbf{H}$ NMR $\left(\mathrm{D}_{2} \mathrm{O}, 400 \mathrm{MHz}\right) \square 5.21$ $(\mathrm{m}, 1 \mathrm{H}), 4.33(\mathrm{~m}, 2 \mathrm{H}), 4.17(\mathrm{~m}$, $1 \mathrm{H}), 4.00(\mathrm{bs}, 2 \mathrm{H}), 3.90(\mathrm{~m}, 2 \mathrm{H})$, $3.67(\mathrm{~m}, 2 \mathrm{H}), 3.31(\mathrm{t}, J=9.0,1 \mathrm{H})$, $2.33(\mathrm{~m}, 2 \mathrm{H}), 2.25(\mathrm{t}, \mathrm{J}=7.3,2 \mathrm{H})$, $1.52(\mathrm{~m}, 4 \mathrm{H}), 1.19(\mathrm{~m}, 16 \mathrm{H}), 0.77(\mathrm{~m}, 6 \mathrm{H}) ;{ }^{31} \mathbf{P}$ NMR $\left(\mathrm{D}_{2} \mathrm{O}, 162 \mathrm{MHz}\right) \square 0.3,3.1 ;[\square]_{\mathrm{D}}=+4.7$ $\left(2.1, \mathrm{H}_{2} \mathrm{O}\right.$ at $\left.\mathrm{pH}=9\right)$; Exact mass calcd for $\left[\mathrm{C}_{25} \mathrm{H}_{47} \mathrm{O}_{16} \mathrm{P}_{2}-\mathrm{H}\right]$ - requires $m / z$ 665.2339. Found 665.2347 (ESI-).

\section{3-PIP(C8)}<smiles>CCCCCCCC(=O)OCC(COP(=O)([O-])O[C@@H]1[C@@H](O)[C@@H](OP(=O)([O-])[O-])[C@H](O)[C@@H](O)[C@@H]1O)OC(=O)CCCCCC</smiles>

Synthesis carried out with $\mathrm{Pd}(\mathrm{OH})_{2} / \mathrm{C}, \mathrm{H}_{2}$ (1 atm), $\mathrm{NaHCO}_{3}, t$ $\mathrm{BuOH} / \mathrm{H}_{2} \mathrm{O}(5: 1), 24$ hrs. We found these conditions more consistently gave analytical pure material.

Spectral data identical to ent-PI3P(C8) $[\square]_{\mathbf{D}}=-4.5\left(2.9, \mathrm{H}_{2} \mathrm{O}\right.$ at $\left.\mathrm{pH}=9\right)$.

\section{Synthesis of Phosphatidyl Inositol with para-Methoxybenzyl Ethers}

\section{Synthesis of 1-O-Diphenylphosphate-2,4,6-O-tri-para-methoxylbenzyl-D-myo-inositol} (11)

Triol 10 (1.40 g, $2.80 \mathrm{mmol})$ was dissolved in $25 \mathrm{~mL}$ of toluene. The solution was warmed until the reaction was homogenous. Once cooled to RT, peptide $3(0.62 \mathrm{mg}, 0.056 \mathrm{mmol}$, in 
$0.50 \mathrm{~mL}$ of $\left.\mathrm{CH}_{2} \mathrm{Cl}_{2}\right)$ was added followed by addition of triethylamine $(0.78 \mathrm{~mL}, 5.6 \mathrm{mmol})$ and diphenylchlorophosphate $(0.87 \mathrm{~mL}, 4.2 \mathrm{mmol})$. After $16 \mathrm{hrs}$, the reaction was filtered to remove triethylamine salts, quenched with $3 \mathrm{~mL}$ of $\mathrm{MeOH}$ and concentrated under reduced pressure. The crude material was purified by silica gel chromatography eluting with a gradient of $20 \%$ ethyl acetate/hexanes to $80 \%$ ethyl acetate/hexanes to yield $1.40 \mathrm{~g}(65 \%$ yield) of $\mathbf{1 0}$ as a viscous oil, which was found to exhibit $>98 \%$ ee.

1-O-Diphenylphosphate-2,4,6-O-tri-para-methoxylbenzyl-D-myo-inositol (11)

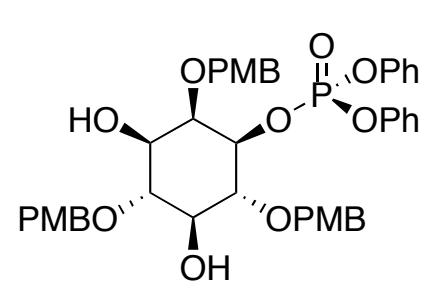

${ }^{1} \mathbf{H}$ NMR $\left(\mathrm{CDCl}_{3}, 400 \mathrm{MHz}\right) \square 7.29-6.70(\mathrm{~m}, 22 \mathrm{H}), 4.82-4.58$ $(\mathrm{m}, 6 \mathrm{H}), 4.55(\mathrm{~m}, 1 \mathrm{H}), 4.21(\mathrm{t}, J=2.4 \mathrm{~Hz}, 1 \mathrm{H}), 3.90(\mathrm{t}, J=9.5 \mathrm{~Hz}$, $1 \mathrm{H}), 3.82(\mathrm{~s}, 3 \mathrm{H}), 3.80(\mathrm{~s}, 3 \mathrm{H}), 3.77(\mathrm{~s}, 3 \mathrm{H}), 3.69-3.49(\mathrm{~m}, 3 \mathrm{H})$, $2.39(\mathrm{~d}, J=1.8 \mathrm{~Hz}, 1 \mathrm{H}), 2.17(\mathrm{~d}, J=5.1 \mathrm{~Hz}, 1 \mathrm{H}) ;{ }^{13} \mathbf{C} \mathbf{N M R}$ $\left(\mathrm{CDCl}_{3}, 100 \mathrm{MHz}\right) \square 159.0,158.9,158.9,150.3,150.2,150.1,130.5,130.2,129.6,129.5$, 129.4, 129.3, 129.2, 129.1, 129.0, 125.2, 125.1, 119.9, 119.9, 119.8, 119.8, 113.7, 113.6, $113.5,80.4,79.8,79.8,79.7,79.6,78.6,74.9,74.8,74.6,74.4,71.6,55.2,55.1{ }^{31} \mathbf{P}$ NMR $\left(\mathrm{CDCl}_{3}, 162 \mathrm{MHz}\right) \square-11.3$; IR (film, $\left.\mathrm{cm}^{-1}\right)$ 3427, 2936, 1614, 1507, 1488, 1243; TLC R 0.18 (50\% ethyl acetate/hexanes); $[\square]_{\mathrm{D}}=+3.6\left(1.0, \mathrm{CH}_{2} \mathrm{Cl}_{2}\right.$, at $>98 \%$ ee $)$; Exact mass calcd for $\left[\mathrm{C}_{42} \mathrm{H}_{45} \mathrm{O}_{12} \mathrm{P}+\mathrm{Na}\right]+$ requires $\mathrm{m} / z$ 795.2535. Found 795.2540 (ESI+). Assay of enantiomeric purity. Enantiomers of 11 were separated utilizing a Chiracel OD column (Alltech), eluting with $30 \%$ ethanol/hexanes at a flow rate of $0.5 \mathrm{~mL} / \mathrm{min}$. Retention times $\mathrm{R}_{\mathrm{t}(\min )}=15.2 \mathrm{~min}, \mathrm{R}_{\mathrm{t}(\text { major })}=17.9 \mathrm{~min}$.

\section{Synthesis of 3,5-O-bis(tert-Butyldimethylsilyl)-1-O-Diphenylphosphate-2,4,6-O-tri-para- methoxylbenzyl-D-myo-inositol}

1-O-Diphenylphosphate-2,4,6-O-tri-para-methoxylbenzyl-D-myo-inositol (11) (1.4 g, 1.8 mmol) was dissolved in $25 \mathrm{~mL}$ of DMF and tert-butyldimethylsilylchloride (2.7 g, $18 \mathrm{mmol})$ was added followed by imidazole $(2.5 \mathrm{~g}, 36 \mathrm{mmol})$. The reaction was heated to $50{ }^{\circ} \mathrm{C}$ with an oil bath for $46 \mathrm{hrs}$. The reaction was then cooled to ambient temperature and extracted with $100 \mathrm{~mL}$ of diethyl ether and $100 \mathrm{~mL}$ of saturated $\mathrm{NH}_{4} \mathrm{Cl}$. The aqueous layer was extracted with 2 X $100 \mathrm{~mL}$ of diethyl ether and the combined organic layers were dried with $\mathrm{Na}_{2} \mathrm{SO}_{4}$ 
and concentrated under reduced pressure. The crude material was purified by silica gel flash chromatography with a gradient of hexanes to $25 \%$ ethyl acetate/hexanes to yield $1.7 \mathrm{~g}$ (89\% yield) of an oily solid.

\section{3,5-O-bis(tert-Butyldimethylsilyl)-1-O-Diphenylphosphate-2,4,6-O-tri-para- methoxylbenzyl-D-myo-inositol}

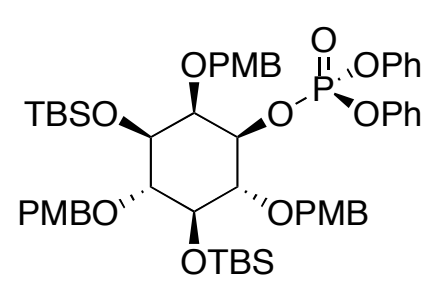

${ }^{1} \mathbf{H}$ NMR $\left(\mathrm{CDCl}_{3}, 400 \mathrm{MHz}\right) \square 7.29-7.07(\mathrm{~m}, 16 \mathrm{H}), 6.90(\mathrm{~d}, J=$ $8.4,2 \mathrm{H}), 6.82(\mathrm{~d}, J=8.4 \mathrm{~Hz}, 2 \mathrm{H}), 6.75(\mathrm{~d}, J=8.8 \mathrm{~Hz}, 2 \mathrm{H}), 4.84(\mathrm{~m}$, 2H), $4.68(\mathrm{~m}, 3 \mathrm{H}), 4.56(\mathrm{~m}, 1 \mathrm{H}), 4.43(\mathrm{~d}, J=10.6 \mathrm{~Hz}, 1 \mathrm{H}), 4.09(\mathrm{t}$, $J=2.2 \mathrm{~Hz}, 1 \mathrm{H}), 3.88(\mathrm{t}, J=9.5 \mathrm{~Hz}, 1 \mathrm{H}), 3.83(\mathrm{~s}, 3 \mathrm{H}), 3.79(\mathrm{~s}, 3 \mathrm{H})$, $3.75(\mathrm{~s}, 3 \mathrm{H}), 3.68(\mathrm{~m}, 2 \mathrm{H}), 3.51(\mathrm{t}, J=8.8 \mathrm{~Hz}, 1 \mathrm{H}), 0.82(\mathrm{~s}, 9 \mathrm{H}), 0.79(\mathrm{~s}, 9 \mathrm{H}), 0.08(\mathrm{~s}, 3 \mathrm{H}),-$ 0.01 (s, 3H), -0.09 (s, 3H), -0.13 (s, 3H); ${ }^{13} \mathbf{C ~ N M R ~}\left(\mathrm{CDCl}_{3}, 100 \mathrm{MHz}\right) \square 159.3,158.8,158.4$, $150.8,150.7,131.5,131.5,131.0,130.0,129.8,129.2$, 129.0, 127.7, 125.6, 125.4, 120.3, $120.3,120.1,120.1,113.9,113.5,113.4,81.8,80.8,80.6,80.6,80.2$, 80.1, 75.5, 75.5, 75.1, 75.0, 74.3, 55.7, 55.5, 26.5, 26.4, 18.5, -3.3, -3.7, -4.3 ${ }^{31} \mathbf{P} \mathbf{N M R}\left(\mathrm{CDCl}_{3}, 162 \mathrm{MHz}\right) \square-11.2$; IR (film, $\mathrm{cm}^{-1}$ ) 2923, 2854, 2067, 1879, 1608, 1513, 1356, 1243; TLC R 0.28 (20\% ethyl acetate/hexanes); $[\mathrm{[}]_{\mathrm{D}}=-24.2\left(1.0, \mathrm{CH}_{2} \mathrm{Cl}_{2}\right.$, at $>98 \%$ ee $)$; Exact mass calcd for $\left[\mathrm{C}_{54} \mathrm{H}_{73} \mathrm{O}_{12} \mathrm{Si}_{2} \mathrm{P}+\mathrm{Na}\right]+$ requires $m / z$ 1023.4276. Found 1023.4258 (ESI+).

\section{Synthesis of 3,5-O-bis(tert-Butyldimethylsilyl)-1- $O$-dibenzylphosphate-2,4,6-O-tri-para- methoxylbenzyl-D-myo-inositol}

3,5-O-bis(tert-Butyldimethylsilyl)-1-O-diphenylphosphate-2,4,6-O-tri-para-methoxylbenzylD-myo-inositol (1.57 g, $1.57 \mathrm{mmol})$ was dissolved in $50 \mathrm{~mL}$ of THF and benzyl alcohol (0.490 $\mathrm{mL}, 4.74 \mathrm{mmol})$ was added followed by portionwise addition of sodium hydride $(0.150 \mathrm{~g}, 6.25 \mathrm{mmol})$. After $20 \mathrm{~min}$ the reaction was complete by TLC so the reaction was quenched with $0.5 \mathrm{M}$ citric acid until the $\mathrm{pH}$ was neutral and then concentrated under reduced pressure. The crude residue was extracted with $100 \mathrm{~mL}$ of diethyl ether and $100 \mathrm{~mL}$ of brine. The aqueous layer was washed with $2 \mathrm{X} 100 \mathrm{~mL}$ of diethyl ether and the combined organic layers were dried with $\mathrm{Na}_{2} \mathrm{SO}_{4}$ and concentrated under reduced pressure. The crude 
product was purified by silica gel flash chromatography with a gradient of $20 \%$ ethyl acetate/hexanes to $30 \%$ ethyl acetate/hexanes to yield $1.60 \mathrm{~g}$ (99\% yield) of an oily solid.

\section{3,5-O-bis(tert-Butyldimethylsilyl)-1-O-dibenzylphosphate-2,4,6-O-tri-para- methoxylbenzyl-D-myo-inositol}

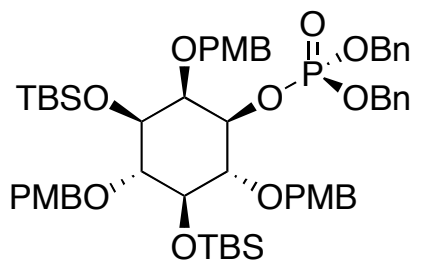

${ }^{1} \mathbf{H}$ NMR $\left(\mathrm{CDCl}_{3}, 400 \mathrm{MHz}\right) \square 7.31-7.17(\mathrm{~m}, 16 \mathrm{H}), 6.87(\mathrm{~d}, J=$

$8.9 \mathrm{~Hz}, 2 \mathrm{H}), 6.82(\mathrm{~d}, J=8.8 \mathrm{~Hz}, 2 \mathrm{H}), 6.75(\mathrm{~d}, J=8.8 \mathrm{~Hz}, 2 \mathrm{H})$, $4.89(\mathrm{~m}, 6 \mathrm{H}), 4.69(\mathrm{~m}, 3 \mathrm{H}), 4.61(\mathrm{~d}, J=10.6 \mathrm{~Hz}, 1 \mathrm{H}), 4.22(\mathrm{~m}$, $1 \mathrm{H}), 4.11(\mathrm{t}, J=2.2 \mathrm{~Hz}, 1 \mathrm{H}), 3.82(\mathrm{t}, J=9.5 \mathrm{~Hz}, 1 \mathrm{H}), 3.81(\mathrm{~s}$, $3 \mathrm{H}), 3.80(\mathrm{~s}, 3 \mathrm{H}), 3.73(\mathrm{~s}, 3 \mathrm{H}), 3.68(\mathrm{t}, J=9.3,1 \mathrm{H}), 3.55(\mathrm{dd}, J=$ $2.2 \mathrm{~Hz}, J=9.9 \mathrm{~Hz}, 1 \mathrm{H}), 3.44(\mathrm{t}, J=9.0 \mathrm{~Hz}, 1 \mathrm{H}), 0.81(\mathrm{~s}, 9 \mathrm{H}), 0.80(\mathrm{~s}, 9 \mathrm{H}), 0.03(\mathrm{~s}, 3 \mathrm{H}),-0.04$ (s, 3H), -0.04 (s, 3H), -0.13 (s, 3H); ${ }^{13} \mathbf{C ~ N M R ~}\left(\mathrm{CDCl}_{3}, 100 \mathrm{MHz}\right) \square$ 158.7, 158.4, 157.9, 135.6, 135.5, 131.2, 130.7, 128.7, 128.3, 128.3, 128.2, 128.2, 127.7, 127.5, 127.2, 113.4, $113.2,112.9,81.4,80.3,80.0,79.9,78.9,78.8,75.2,75.0,74.9,74.5,73.8,69.2,69.2,69.0$, 68.9, 55.2, 55.0, 26.1, 25.9, 18.0, 18.0, -3.8, -4.2, -4.7; ${ }^{31} \mathbf{P} \mathbf{N M R}\left(\mathrm{CDCl}_{3}, 162 \mathrm{MHz}\right) \square-0.3$; IR (film, $\mathrm{cm}^{-1}$ ) 2961, 2860, 2363, 1614, 1507, 1463, 1243; TLC $\mathbf{R}_{f} 0.17$ (20\% ethyl acetate/hexanes); $[\square]_{\mathrm{D}}=-26.8\left(1.0, \mathrm{CH}_{2} \mathrm{Cl}_{2}\right.$, at $>98 \%$ ee); Exact mass calcd for $\left[\mathrm{C}_{56} \mathrm{H}_{77} \mathrm{O}_{12} \mathrm{Si}_{2} \mathrm{P}+\mathrm{Na}\right]+$ requires $m / z$ 1051.4589. Found 1051.4587 (ESI+).

\section{Synthesis of 1-O-dibenzylphosphate-2,4,6-O-tri-para-methoxylbenzyl-D-myo-inositol} (12)

3,5-O-bis(tert-butyldimethylsilyl)-1-O-dibenzylphosphate-2,4,6-O-tri-para-methoxylbenzylD-myo-inositol $(0.80 \mathrm{~g}, 0.78 \mathrm{mmol})$ was dissolved in $20 \mathrm{~mL}$ of THF and cooled to $0{ }^{\circ} \mathrm{C}$. HF.pyridine $(4.0 \mathrm{~mL})$ was added and the reaction slowly warmed to ambient temperature. The reaction was stirred for 48 hrs until TLC showed complete conversion and then the solution was cooled to $0{ }^{\circ} \mathrm{C}$ and quenched with saturated $\mathrm{NaHCO}_{3}$ until the reaction was basic. The mixture was then washed with $3 \mathrm{X} 150 \mathrm{~mL}$ of $\mathrm{CH}_{2} \mathrm{Cl}_{2}$. The combined organic layers were dried with $\mathrm{Na}_{2} \mathrm{SO}_{4}$ and concentrated under reduced pressure. The crude product 
was purified by silica gel flash chromatography with a gradient of $50 \%$ ethyl acetate/hexanes to $80 \%$ ethyl acetate/hexanes to yield $0.48 \mathrm{~g}$ (77\% yield) of $\mathbf{1 2}$.

\section{1-O-Dibenzylphosphate-2,4,6-O-tri-para-methoxylbenzyl-D-myo-inositol (12)} ${ }^{1} \mathbf{H}$ NMR $\left(\mathrm{CDCl}_{3}, 400 \mathrm{MHz}\right) \square 7.31-7.19(\mathrm{~m}, 16 \mathrm{H}), 6.86(\mathrm{t}, J=$

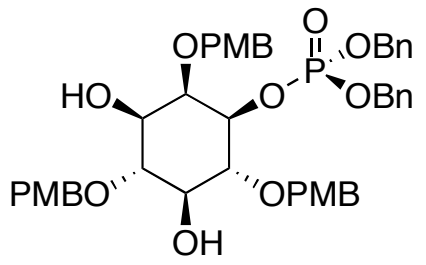
$8.4 \mathrm{~Hz}, 4 \mathrm{H}), 6.80(\mathrm{~d}, J=8.8 \mathrm{~Hz}, 2 \mathrm{H}), 5.00(\mathrm{~m}, 4 \mathrm{H}), 4.70(\mathrm{~m}, 6 \mathrm{H})$, $4.24(\mathrm{~m}, 1 \mathrm{H}), 4.14(\mathrm{t}, J=2.6 \mathrm{~Hz}, 1 \mathrm{H}), 3.84(\mathrm{t}, J=9.5 \mathrm{~Hz}, 1 \mathrm{H})$, $3.80(\mathrm{~s}, 3 \mathrm{H}), 3.79(\mathrm{~s}, 3 \mathrm{H}), 3.75(\mathrm{~s}, 3 \mathrm{H}), 3.60(\mathrm{t}, J=9.3 \mathrm{~Hz}, 1 \mathrm{H})$, $3.42(\mathrm{~m}, 2 \mathrm{H}), 2.51(\mathrm{~d}, J=2.2 \mathrm{~Hz}, 1 \mathrm{H}), 2.15(\mathrm{~d}, J=6.2 \mathrm{~Hz}, 1 \mathrm{H})$; ${ }^{13} \mathbf{C}$ NMR $\left(\mathrm{CDCl}_{3}, 100 \mathrm{MHz}\right) \square 159.1,159.0,135.5,130.5,130.4,129.6,129.4,129.1,128.4$, $128.4,128.4,127.8,113.8,113.7,113.7,80.9,79.7,79.7,78.7,78.6,75.1,74.9,74.6,74.5$, 71.7, 69.5, 69.5, 69.4, 69.3, 55.3, 55.2; ${ }^{31} \mathbf{P}$ NMR $\left(\mathrm{CDCl}_{3}, 162 \mathrm{MHz}\right) \square-0.3$; IR (film, $\left.\mathrm{cm}^{-1}\right)$ 3553, 3414, 2999, 2936, 1608, 1507, 1457, 1243, 1010; TLC $\mathbf{R}_{f} 0.42$ (80\% ethyl acetate/hexanes); $[0]_{\mathbf{D}}=+3.2\left(1.0, \mathrm{CH}_{2} \mathrm{Cl}_{2}\right.$, at $>98 \%$ ee $)$; Exact mass calcd for $\left[\mathrm{C}_{44} \mathrm{H}_{49} \mathrm{O}_{12} \mathrm{P}+\right.$ $\mathrm{Na}]+$ requires $\mathrm{m} / \mathrm{z}$ 823.2859. Found 823.2855 (ESI+). Assay of enantiomeric purity. Enantiomers of 12 were separated utilizing a Chiracel OD column (Alltech), eluting with $30 \%$ ethanol/hexanes at a flow rate of $0.5 \mathrm{~mL} / \mathrm{min}$. Retention times $\mathrm{R}_{\mathrm{t}(\min )}=18.1 \mathrm{~min}, \mathrm{R}_{\mathrm{t}(\mathrm{magor})}$ $=22.0 \mathrm{~min}$.

\section{Synthesis of 3-O-(2-Arachidonyl-3-stearoyl-sn-gycerol-1-benzylphosphate)-1-O-} dibenylphosphate-2,4,6-O-tri-PMB-myo-D-inositol (14)

$12(0.160 \mathrm{~g}, 0.200 \mathrm{mmol})$ was dissolved in $6 \mathrm{~mL}$ of toluene/ $\mathrm{CH}_{2} \mathrm{Cl}_{2}$ (1:1) followed by addition of $13^{7}$ (0.255 g, $\left.0.290 \mathrm{mmol}\right)$ and 4,5-dicyanoimidazole (0.071 g, $\left.0.60 \mathrm{mmol}\right)$. The reaction was stirred for $12 \mathrm{hrs}$ and then cooled to $0{ }^{\circ} \mathrm{C}$ followed by addition of $30 \%$ $\mathrm{H}_{2} \mathrm{O}_{2} / \mathrm{H}_{2} \mathrm{O}(2.0 \mathrm{~mL})$. After $1 \mathrm{hr}$ the reaction was quenched with saturated $\mathrm{Na}_{2} \mathrm{SO}_{3}$ (approximately $50 \mathrm{~mL}$ ) and extracted with $3 \mathrm{X} 50 \mathrm{~mL}$ of $\mathrm{CH}_{2} \mathrm{Cl}_{2}$. The combined organic

\footnotetext{
${ }^{7}$ Synthesized in analogy to (a) Kubiak, R.J.; Bruziak, K.S. J. Org. Chem. 2003, 68, 960-968. (b) Gaffney, P.R.J.; Reese, C.B. J. Chem. Soc., Perkin Trans. 1, 2001, 192-205.
} 
layers were dried with $\mathrm{Na}_{2} \mathrm{SO}_{4}$ and concentrated under reduced pressure. The crude product was purified by silica gel chromatography eluting with a gradient of $20 \%$ ethyl acetate/hexanes to $50 \%$ ethyl acetate/hexanes to yield $0.125 \mathrm{~g}$ (39\% yield) of $\mathbf{1 4}$ as an oily solid.

\section{3-O-(2-Arachidonyl-3-stearoyl-sn-gycerol-1-benzylphosphate)-1- $O$-dibenylphosphate-}

\section{2,4,6-O-tri-PMB-myo-D-inositol (14)}

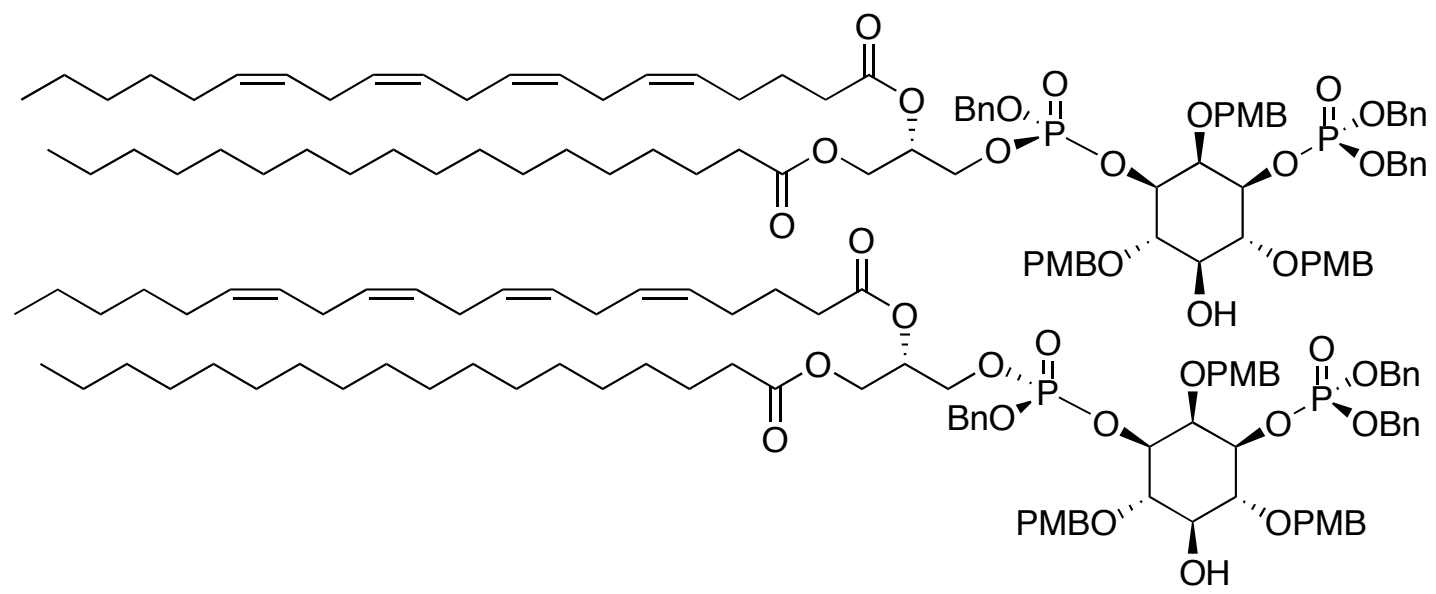

${ }^{1} \mathbf{H}$ NMR $\left(\mathrm{CDCl}_{3}, 400 \mathrm{MHz}\right) \square 7.34-7.23(\mathrm{~m}, 21 \mathrm{H}), 6.90-6.82(\mathrm{~m}, 6 \mathrm{H}), 5.40(\mathrm{~m}, 8 \mathrm{H}), 5.16$ (m, 1H), $5.02(\mathrm{~m}, 6 \mathrm{H}), 4.73(\mathrm{~m}, 6 \mathrm{H}), 4.47(\mathrm{bs}, 1 \mathrm{H}), 4.28(\mathrm{t}, J=9.9 \mathrm{~Hz}, 1 \mathrm{H}), 4.20(\mathrm{t}, J=10.6$ $\mathrm{Hz}, 1 \mathrm{H}), 4.15-3.93(\mathrm{~m}, 4 \mathrm{H}), 3.89$ (t, $J=9.5 \mathrm{~Hz}, 2 \mathrm{H}), 2.84(\mathrm{~m}, 6 \mathrm{H}), 2.35$ (bs, 1H), 2.27 (m, 4H), $2.08(\mathrm{~m}, 4 \mathrm{H}), 1.61(\mathrm{~m}, 4 \mathrm{H}), 1.29(\mathrm{~m}, 34 \mathrm{H}), 0.93(\mathrm{~m}, 6 \mathrm{H}) ;{ }^{13} \mathbf{C} \mathbf{~ N M R}\left(\mathrm{CDCl}_{3}, 100 \mathrm{MHz}\right)$ 口 172.8, 172.1, 159.0, 158.9, 135.5, 130.4, 130.3, 129.4, 129.3, 128.8, 128.7, 128.6, 128.4, $128.4,128.3,128.3,128.2,128.1,127.9,127.7,127.6,127.3,113.7,113.6,113.5,113.4$, 79.2, 78.1, 77.7, 75.4, 74.8, 74.6, 74.3, 69.7, 69.5, 69.4, 69.3, 69.2, 65.5, 61.5, 55.2, 34.0, $33.5,31.9,31.5,29.7,29.7,29.5,29.4,29.3,29.2$, 27.2 26.5, 25.7, 25.7, 25.6, 24.9, 24.7, 22.7, 22.6, 14.7, 14.1; ${ }^{31} \mathbf{P}$ NMR $\left(\mathrm{CDCl}_{3}, 162 \mathrm{MHz}\right) \square-0.4,-0.5,-0.6,-0.7 ; \mathbf{I R}$ (film, $\mathrm{cm}^{-1}$ ) $3408,3011,2923,2855,2363,1740,1614,1513,1457,1243$, 1023; TLC $\mathbf{R}_{f} 0.44$ (50\% ethyl acetate/hexanes); $[\square]_{\mathrm{D}}=-1.0\left(4.3, \mathrm{CH}_{2} \mathrm{Cl}_{2}\right) ;$ Exact mass calcd for $\left[\mathrm{C}_{92} \mathrm{H}_{126} \mathrm{O}_{19} \mathrm{P}_{2}+\mathrm{Na}\right]+$ requires $m / z$ 1619.8267. Found 1619.8270 (ESI+). 


\section{Synthesis of ent-PI3P}

$14(0.025 \mathrm{~g}, 0.016 \mathrm{mmol})$ was dissolved in $1.0 \mathrm{~mL}$ of toluene and bromotrimethylsilane $(0.041 \mathrm{~mL}, 0.31 \mathrm{mmol})$ was added. The reaction was heated to $70{ }^{\circ} \mathrm{C}$ for $12 \mathrm{hrs}$ and was then cooled to $0{ }^{\circ} \mathrm{C}$ and concentrated via vacuum transfer. The residue was dissolved in $1.5 \mathrm{~mL}$ of toluene and then azeotroped at $0^{\circ} \mathrm{C}$ via vacuum transfer. This procedure was repeated twice. The residue was then dissolved in $1 \mathrm{~mL}$ of methanol and stirred at $0{ }^{\circ} \mathrm{C}$ for $1 \mathrm{hr}$. This solution was then concentrated under reduced pressure. The residue was dissolved in a minimal amount of $\mathrm{CH}_{3} \mathrm{OH} / \mathrm{CH}_{2} \mathrm{Cl}_{2}$ (1:1) and purified by silica gel chromatography eluting with $\mathrm{CHCl}_{3} / \mathrm{CH}_{3} \mathrm{OH} / 2.2 \mathrm{M} \mathrm{NH}_{4} \mathrm{OH}(9: 7: 2)^{8}$ to yield $10 \mathrm{mg}$ (61\% yield) of $\boldsymbol{e n t}$-PI3P as the ammonium salt.

\section{ent-PI3P}

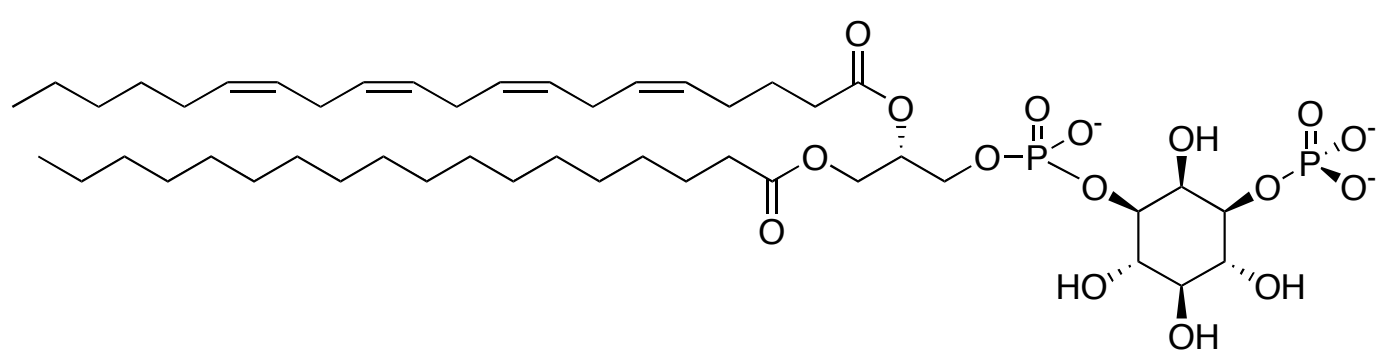

${ }^{1} \mathbf{H}$ NMR $\left(\mathrm{CD}_{3} \mathrm{OD} / \mathrm{CDCl}_{3} / \mathrm{D}_{2} \mathrm{O}(4: 3: 1), 400 \mathrm{MHz}\right) \square 5.40(\mathrm{~m}, 8 \mathrm{H}), 5.30(\mathrm{~m}, 1 \mathrm{H}), 4.42(\mathrm{~m}$, $1 \mathrm{H}), 4.26(\mathrm{~m}, 2 \mathrm{H}), 4.09(\mathrm{~m}, 2 \mathrm{H}), 3.98(\mathrm{~m}, 2 \mathrm{H}), 3.81(\mathrm{~m}, 2 \mathrm{H}), 3.60(\mathrm{~m}, 1 \mathrm{H}), 2.87(\mathrm{~m}, 6 \mathrm{H})$, $2.41(\mathrm{t}, J=8.2 \mathrm{~Hz}, 2 \mathrm{H}), 2.34(\mathrm{~m}, 2 \mathrm{H}), 2.13(\mathrm{~m}, 4 \mathrm{H}), 1.73(\mathrm{~m}, 2 \mathrm{H}), 1.61(\mathrm{~m}, 2 \mathrm{H}), 1.30(\mathrm{~m}$, 34H), $0.91(\mathrm{~m}, 6 \mathrm{H}) ;{ }^{31} \mathbf{P}$ NMR $\left(\mathrm{CD}_{3} \mathrm{OD} / \mathrm{CDCl}_{3} / \mathrm{D}_{2} \mathrm{O}(4: 3: 1), 162 \mathrm{MHz}\right) \square$ 2.6, 0.7; TLC $\mathbf{R}_{f}$ $0.60\left(9: 7: 2 \mathrm{CHCl}_{3} / \mathrm{CH}_{3} \mathrm{OH} / 2.2 \mathrm{M} \mathrm{NH}_{4} \mathrm{OH}\right)$; Exact mass calcd for $\left[\mathrm{C}_{47} \mathrm{H}_{84} \mathrm{O}_{19} \mathrm{P}_{2}-\mathrm{H}\right]$ - requires $\mathrm{m} / z$ 965.5156. Found 965.5129 (ESI-).

The synthesis was also carried out in the natural enantiomer series. The spectral data was found to be the same, and an additional ${ }^{31} \mathrm{P}$ NMR spectrum was recorded in the presence of sodium deoxycholate: ${ }^{31} \mathbf{P}$ NMR $\left(\mathrm{CD}_{3} \mathrm{OD} / \mathrm{CDCl}_{3} / \mathrm{D}_{2} \mathrm{O}(4: 3: 1), 162 \mathrm{MHz}\right) \square$ 2.6, 0.8; $\left(\mathrm{CD}_{3} \mathrm{OD} / \mathrm{CDCl}_{3} / \mathrm{D}_{2} \mathrm{O}(4: 3: 1)\right.$ in the presence of $0.048 \mathrm{mmol}$ sodiumdeoxycholate, $\left.162 \mathrm{MHz}\right)$ ๑5.1, 0.9.

\footnotetext{
${ }^{8}$ Auger, K.R.; Carpenter, C.L.; Cantley, L.C.; Varticovski, L. J. Biol. Chem. 1989, 264, 20181-20184.
} 

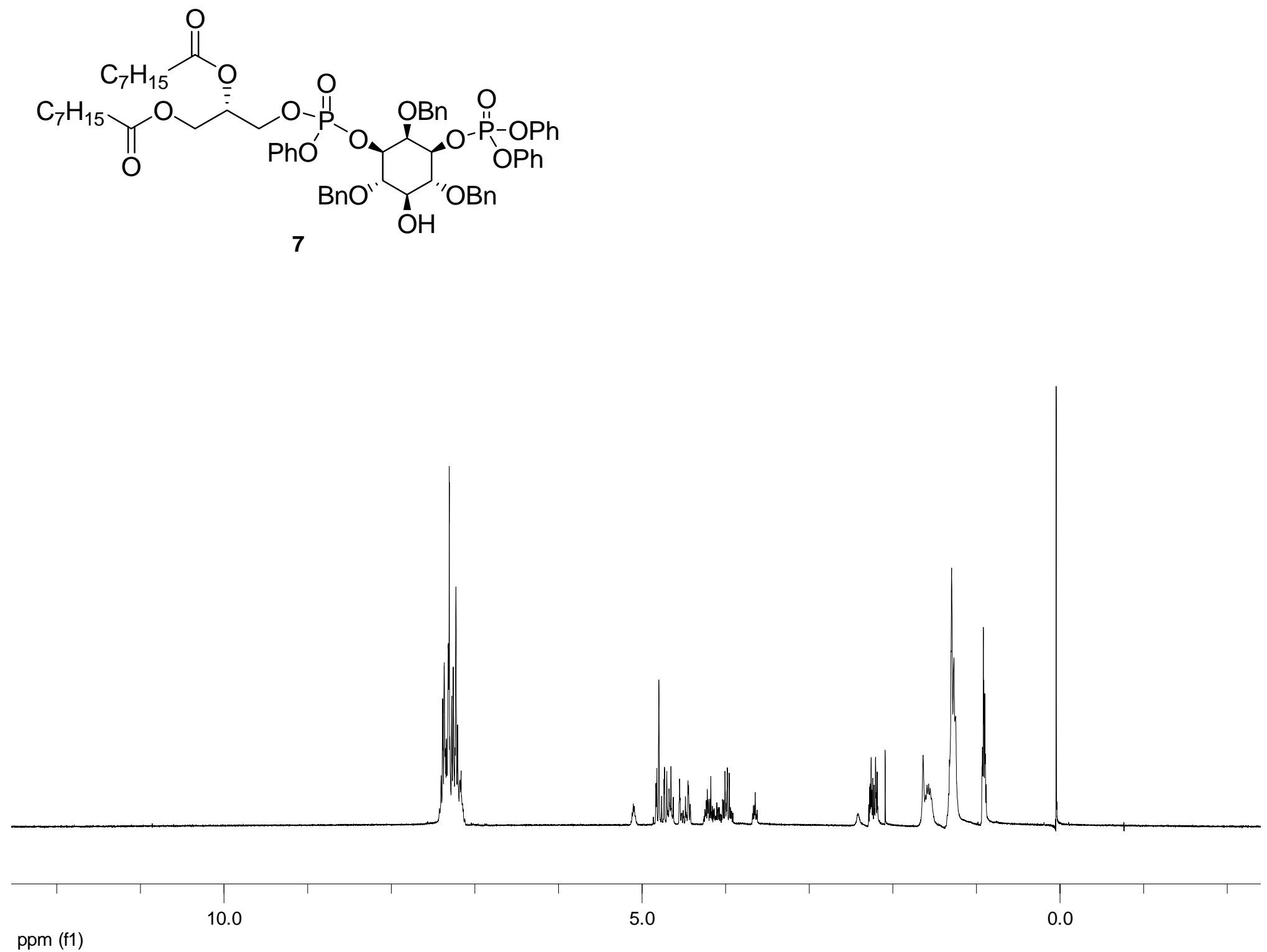

SI- 16 


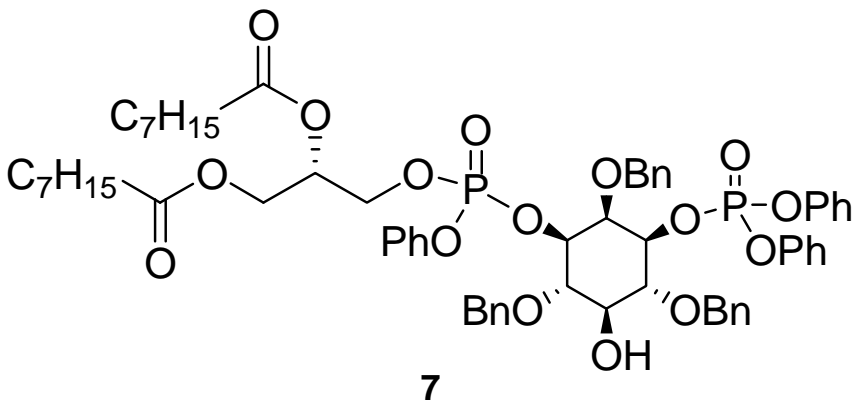

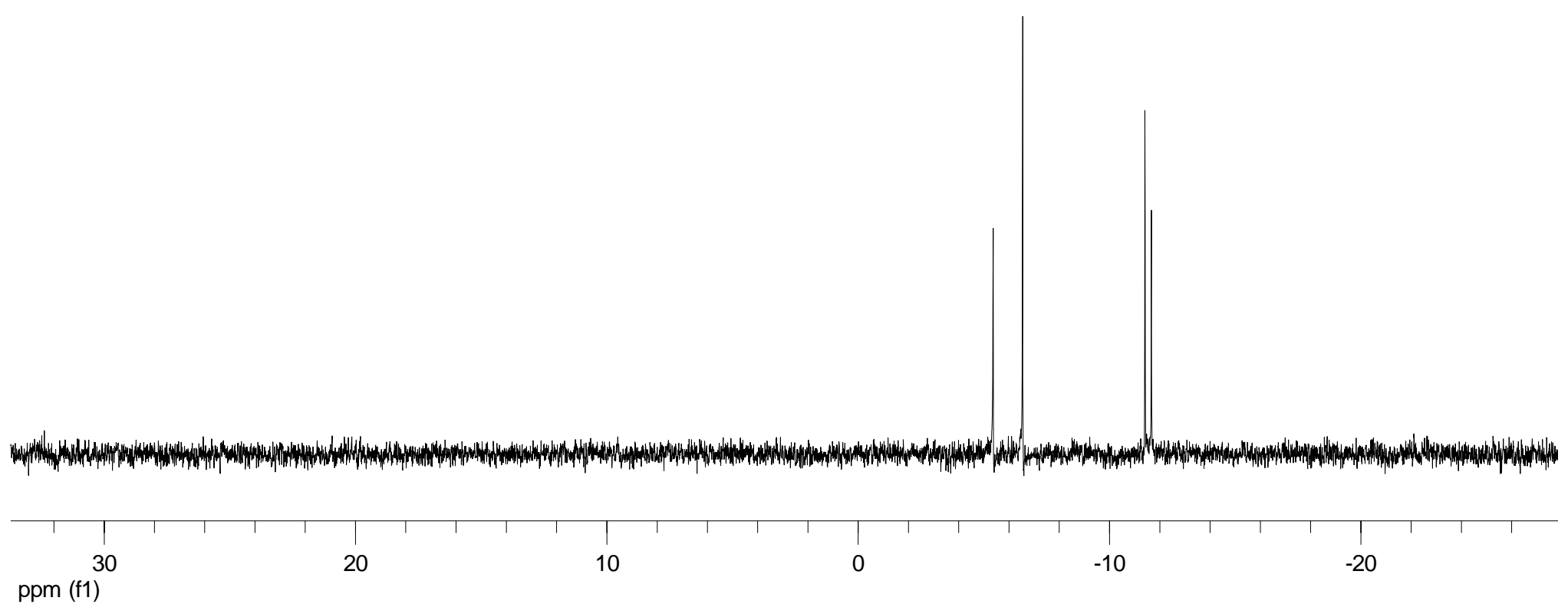



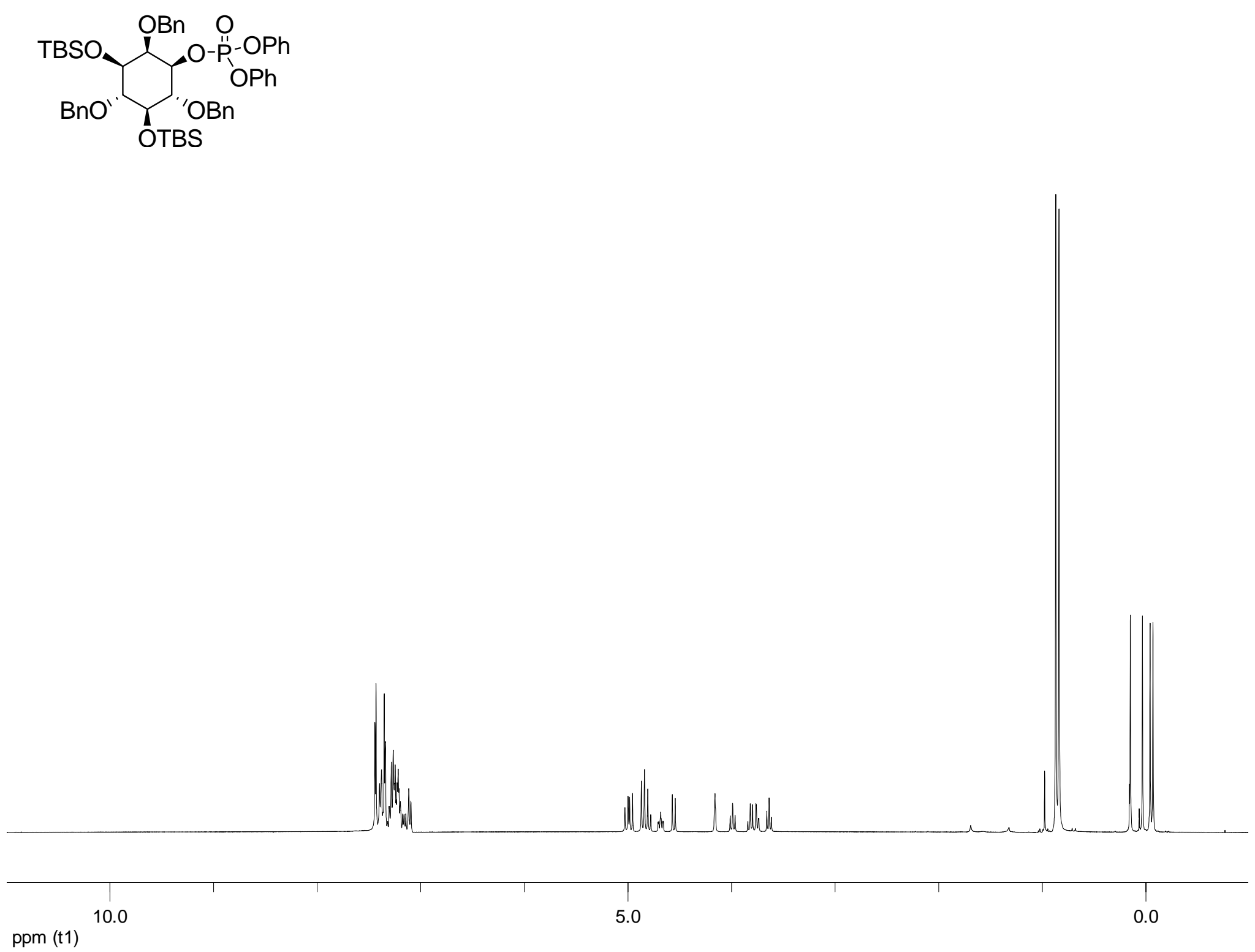

SI- 18 


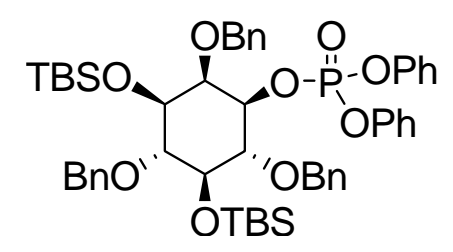

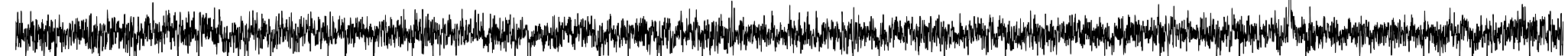

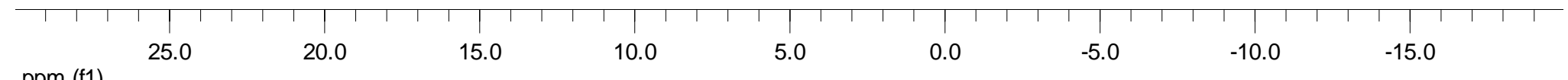

SI- 19 

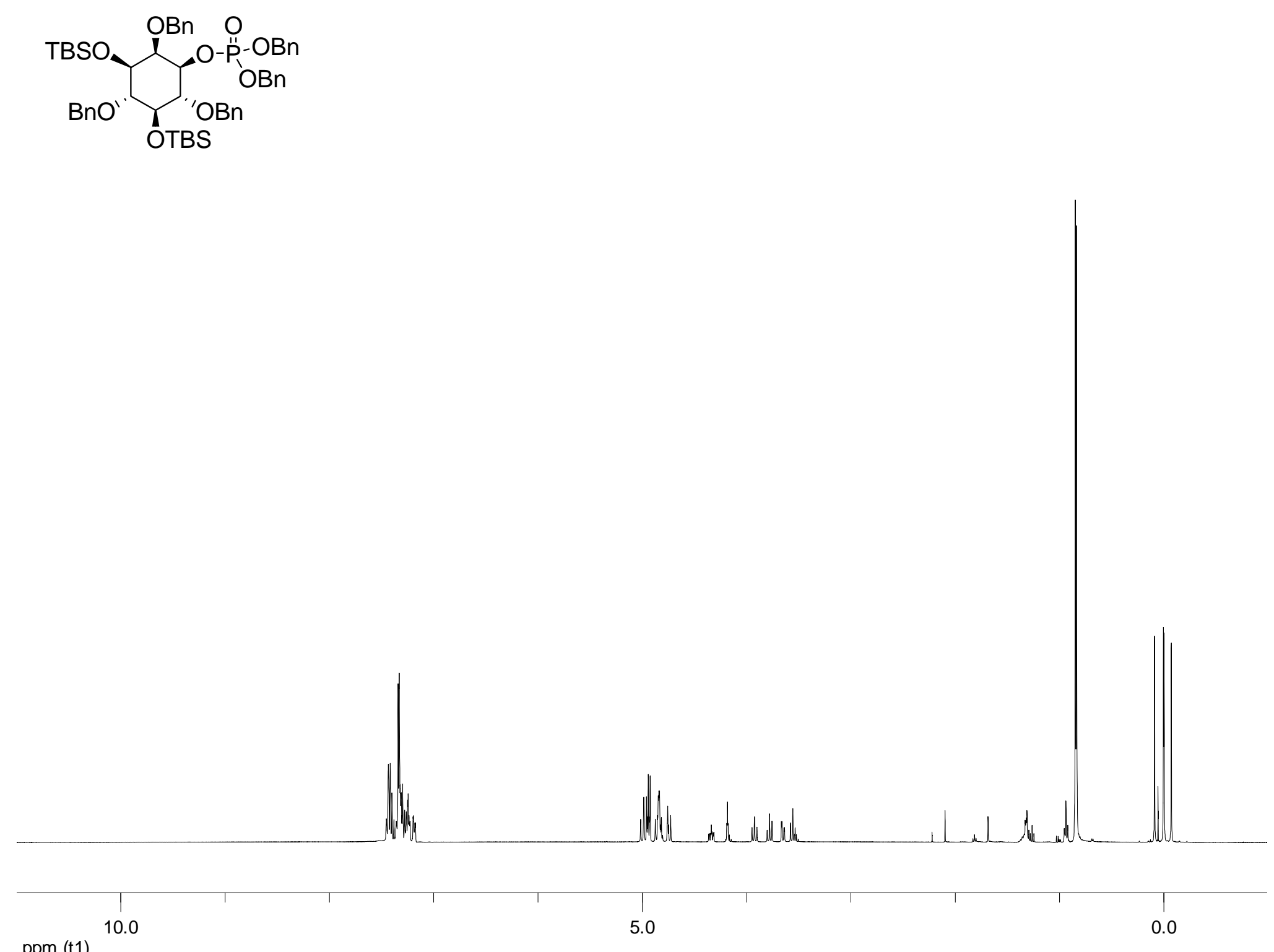

SI- 20 

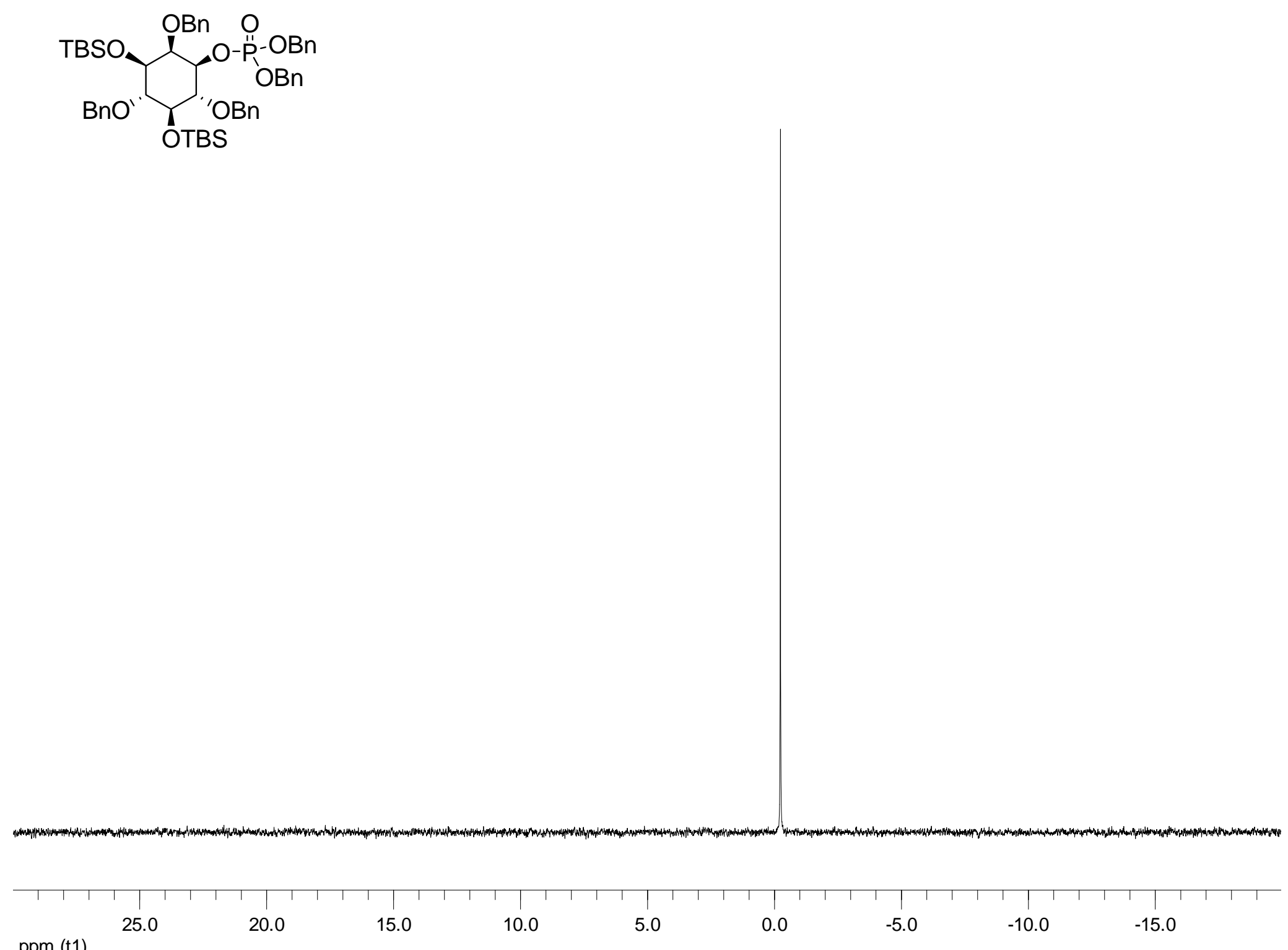

SI- 21 


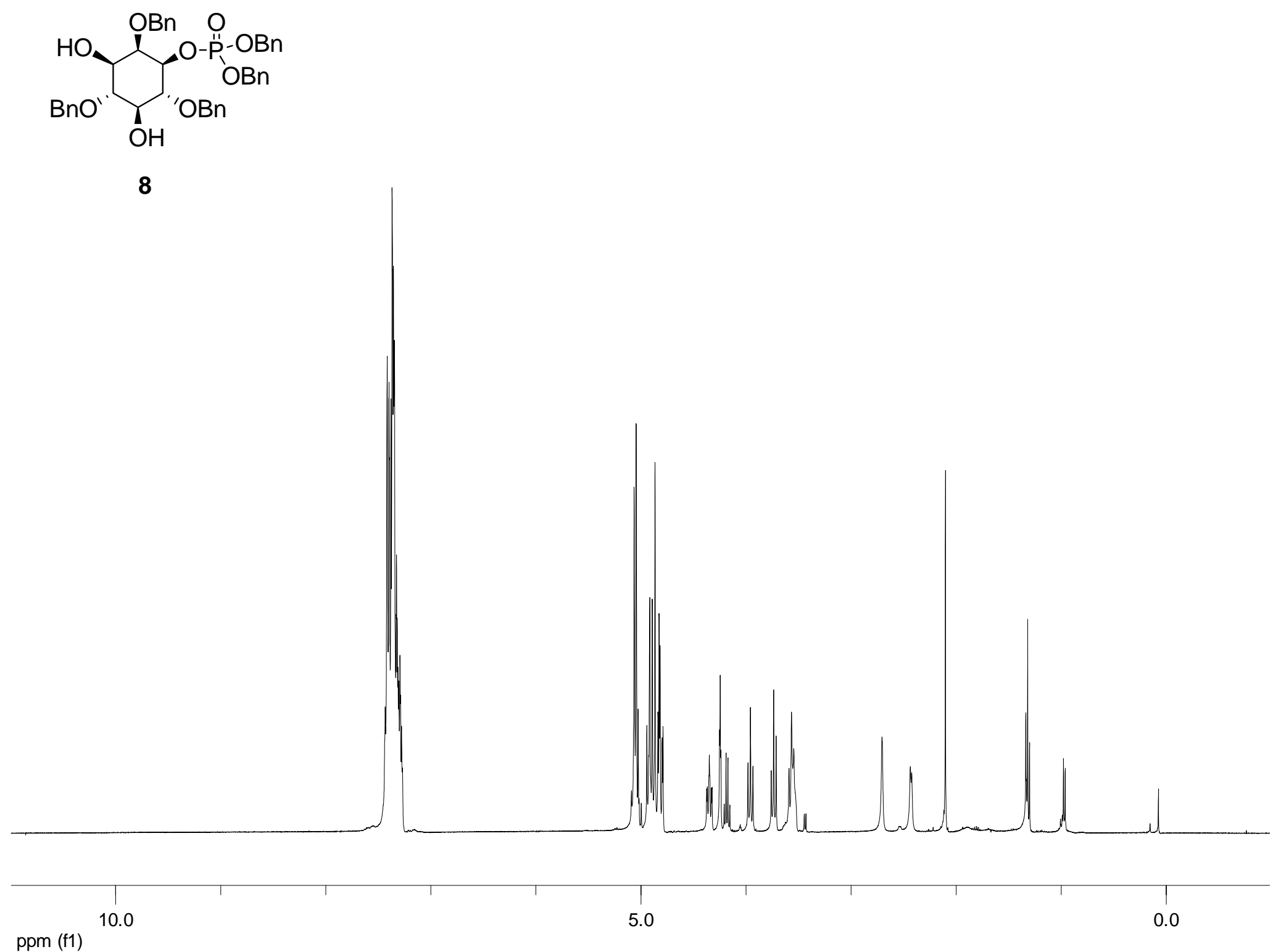

SI- 22 


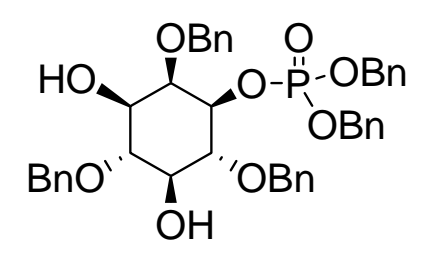

8

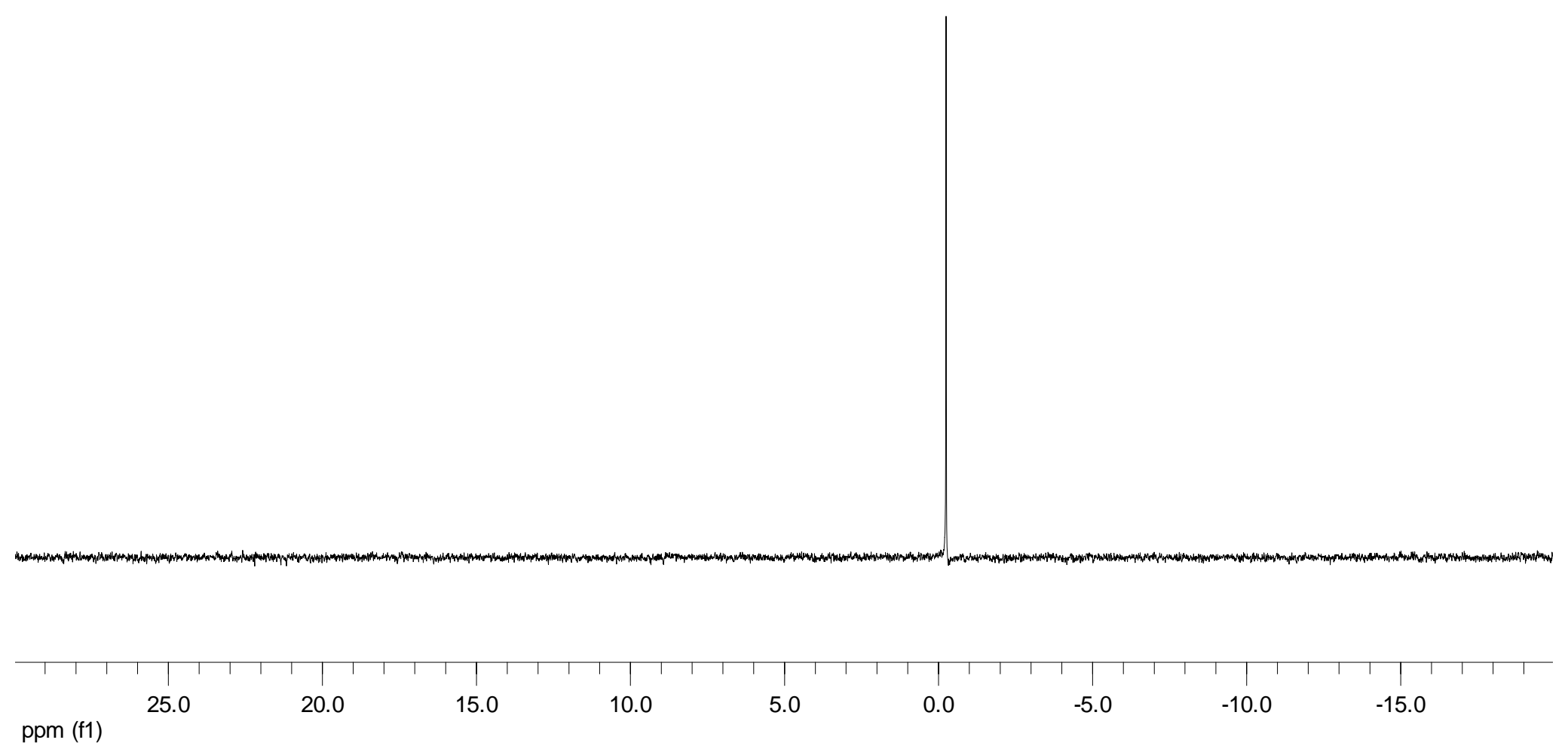

SI- 23 

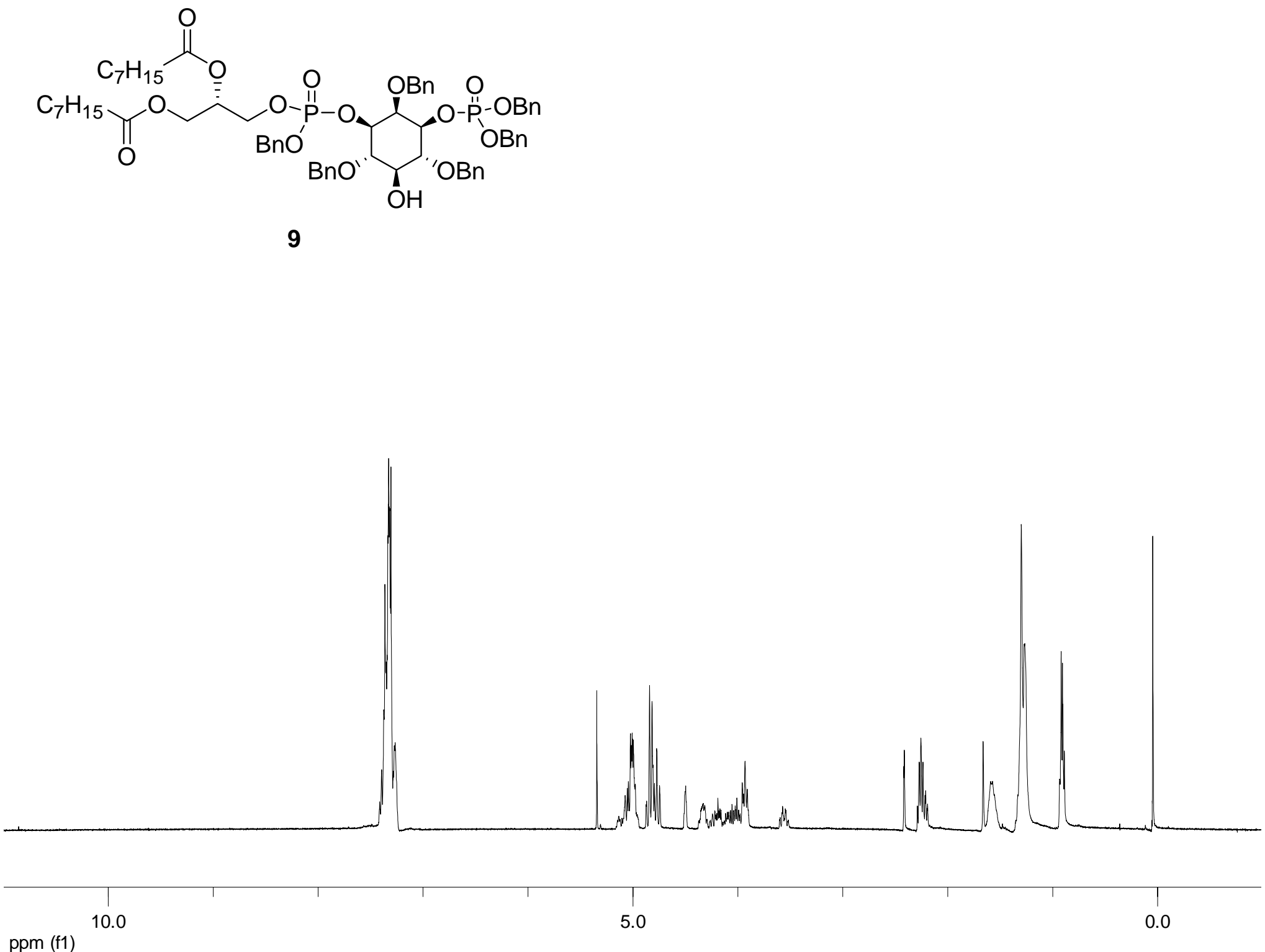

SI- 24 


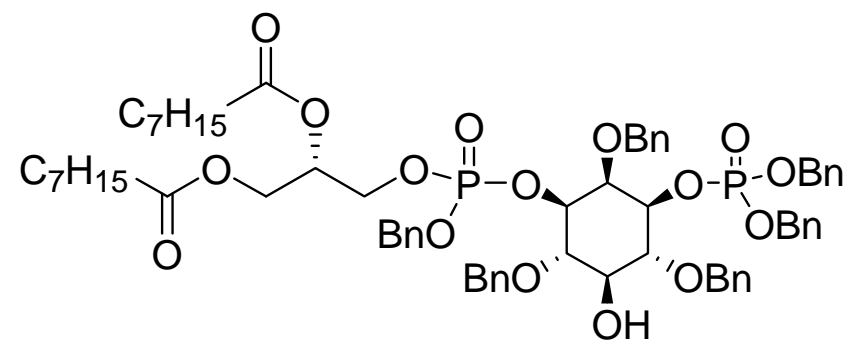

9

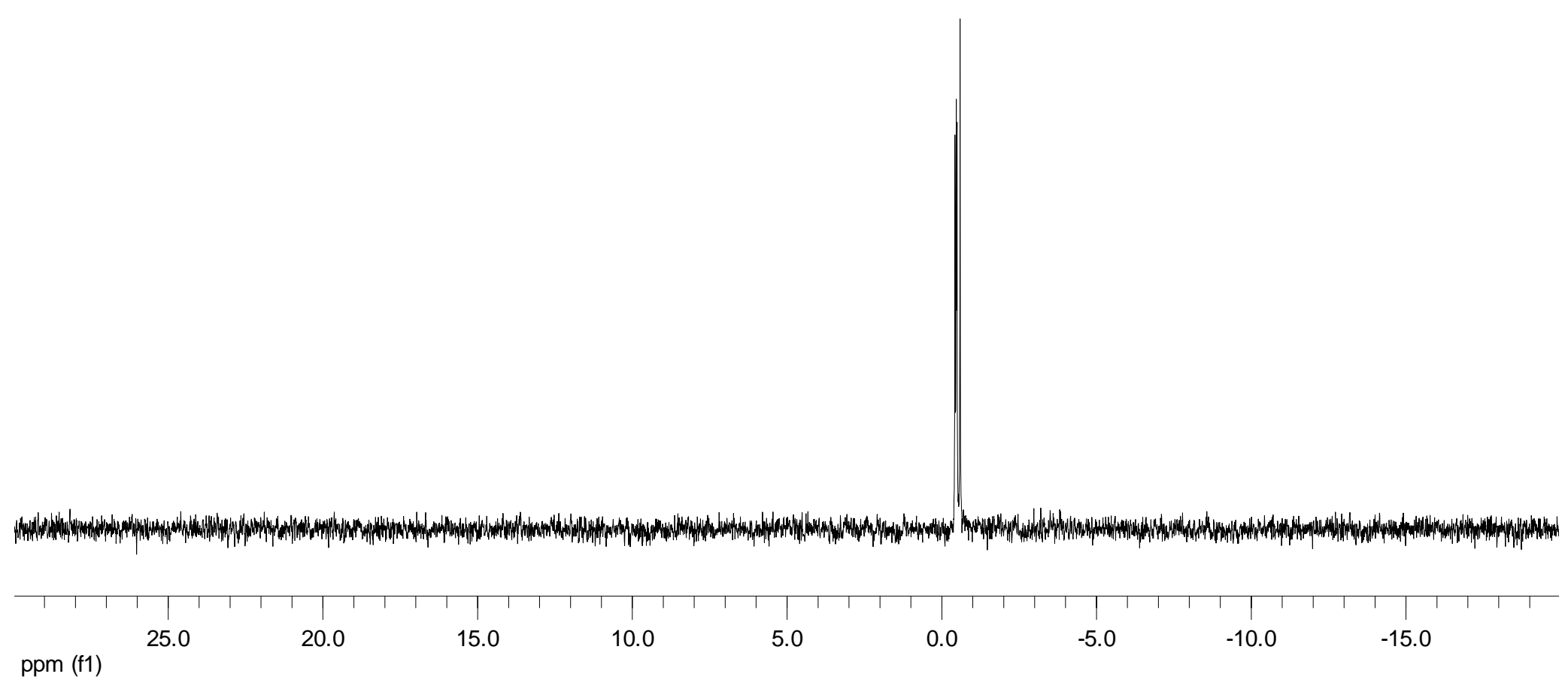

SI- 25 


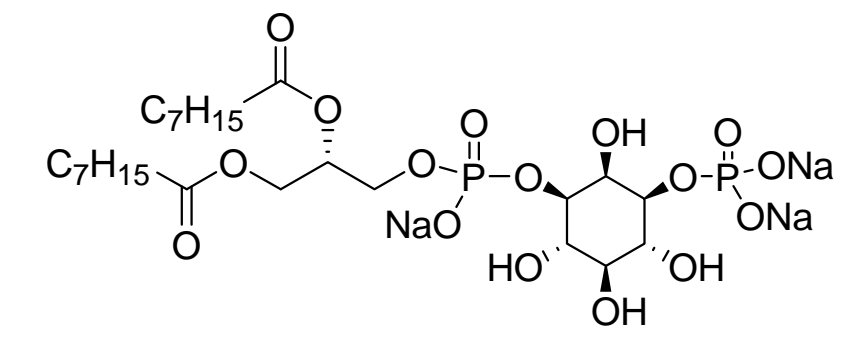

ent-PI3P

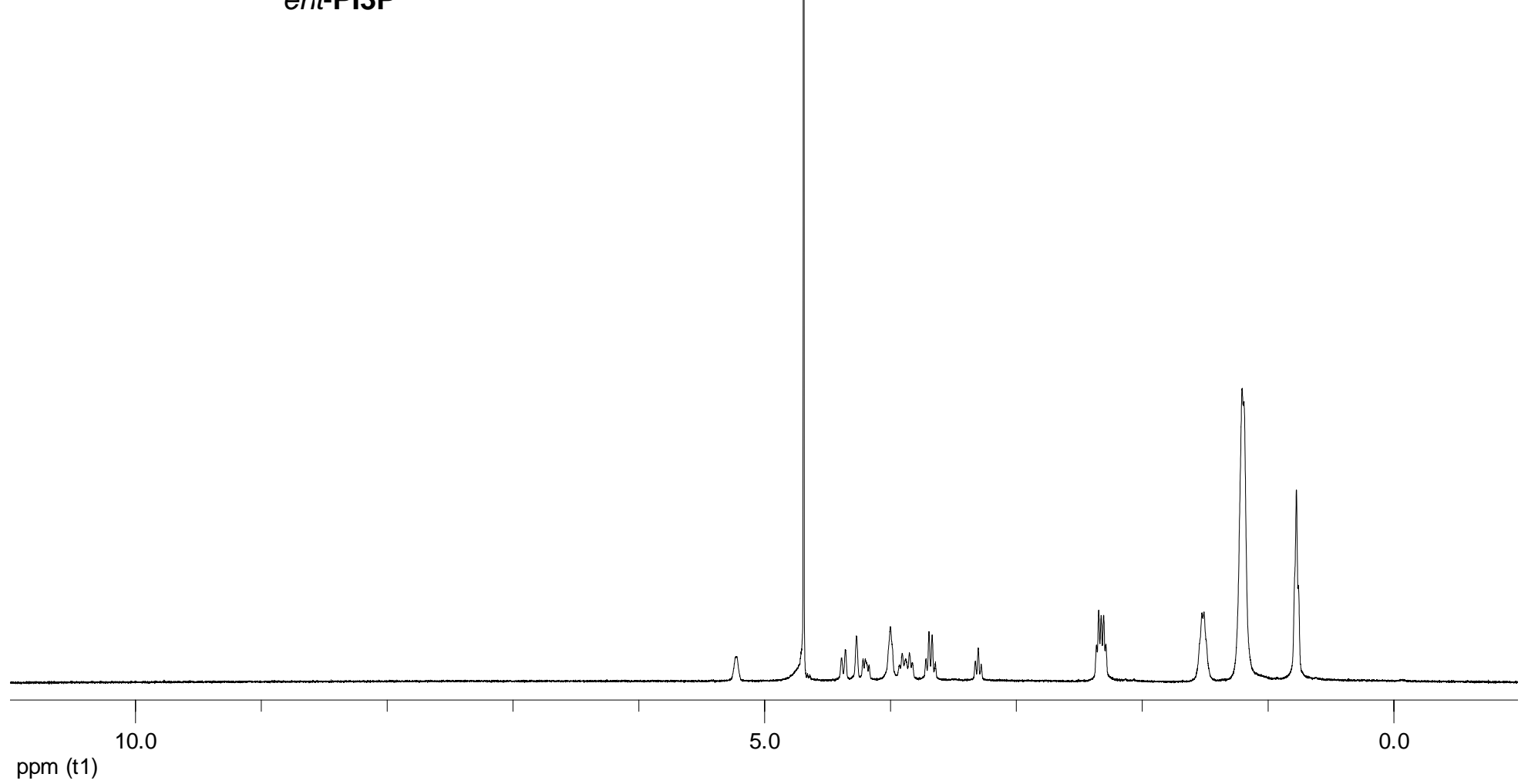

SI- 26 


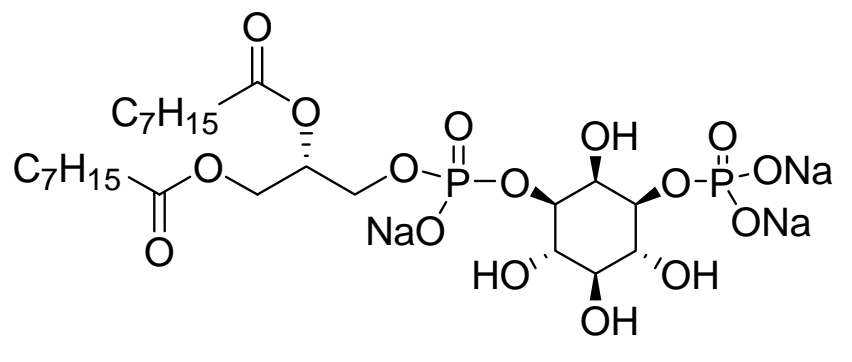

ent-PI3P

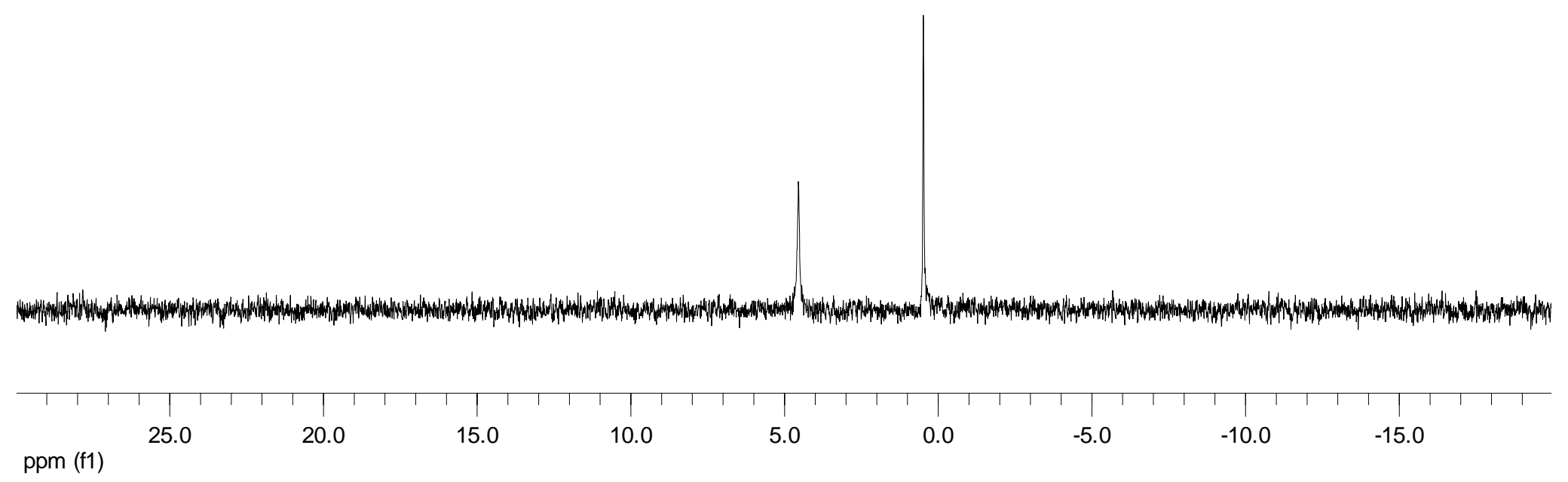



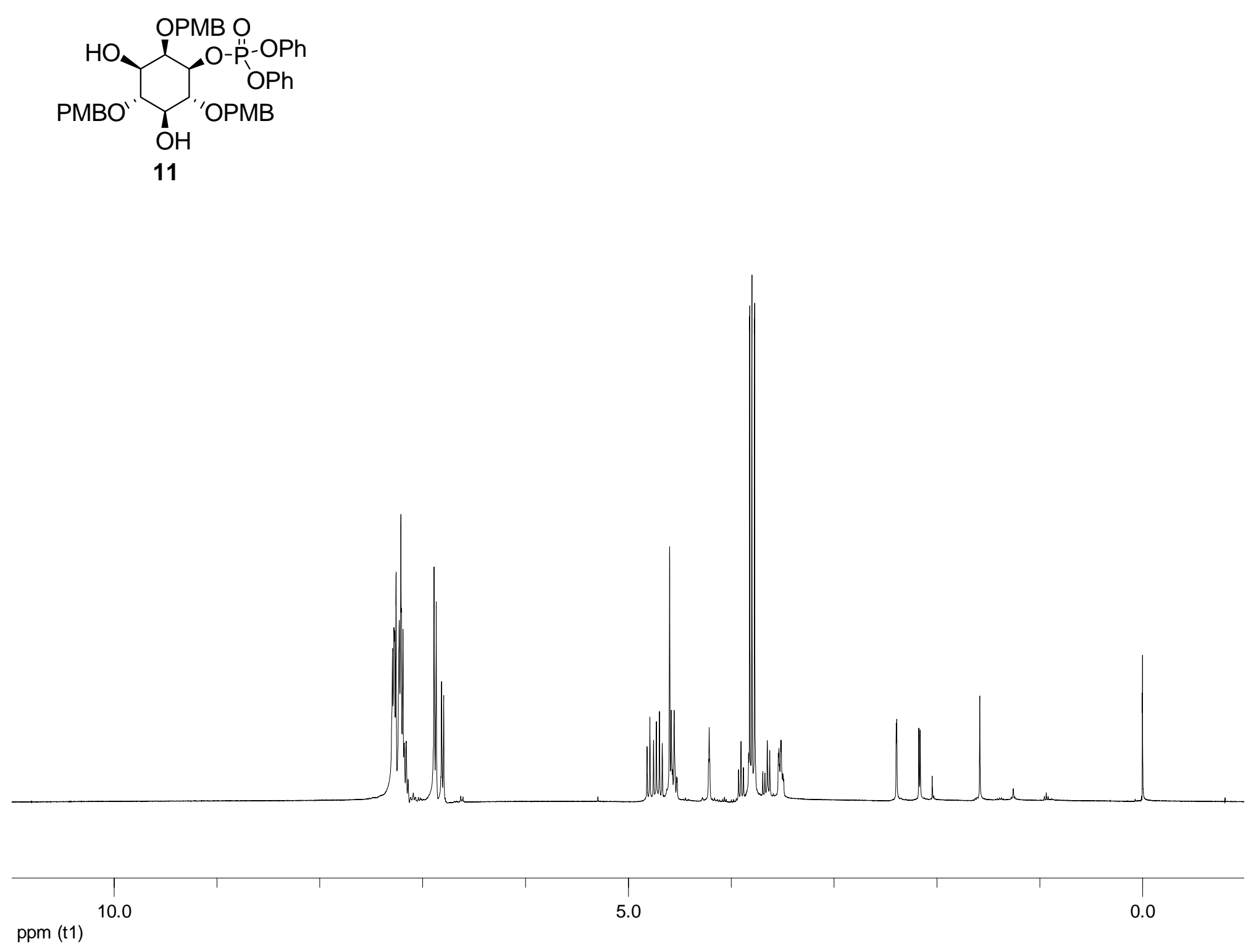

SI- 28 


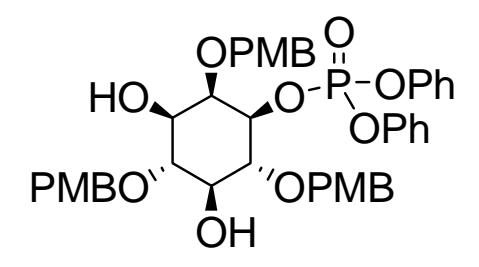

11

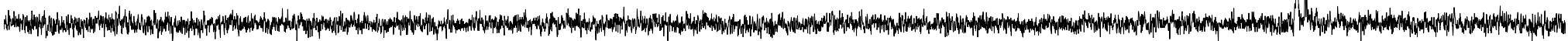

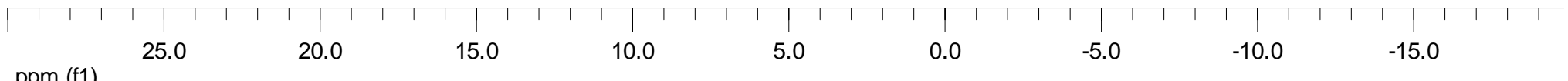

SI- 29 

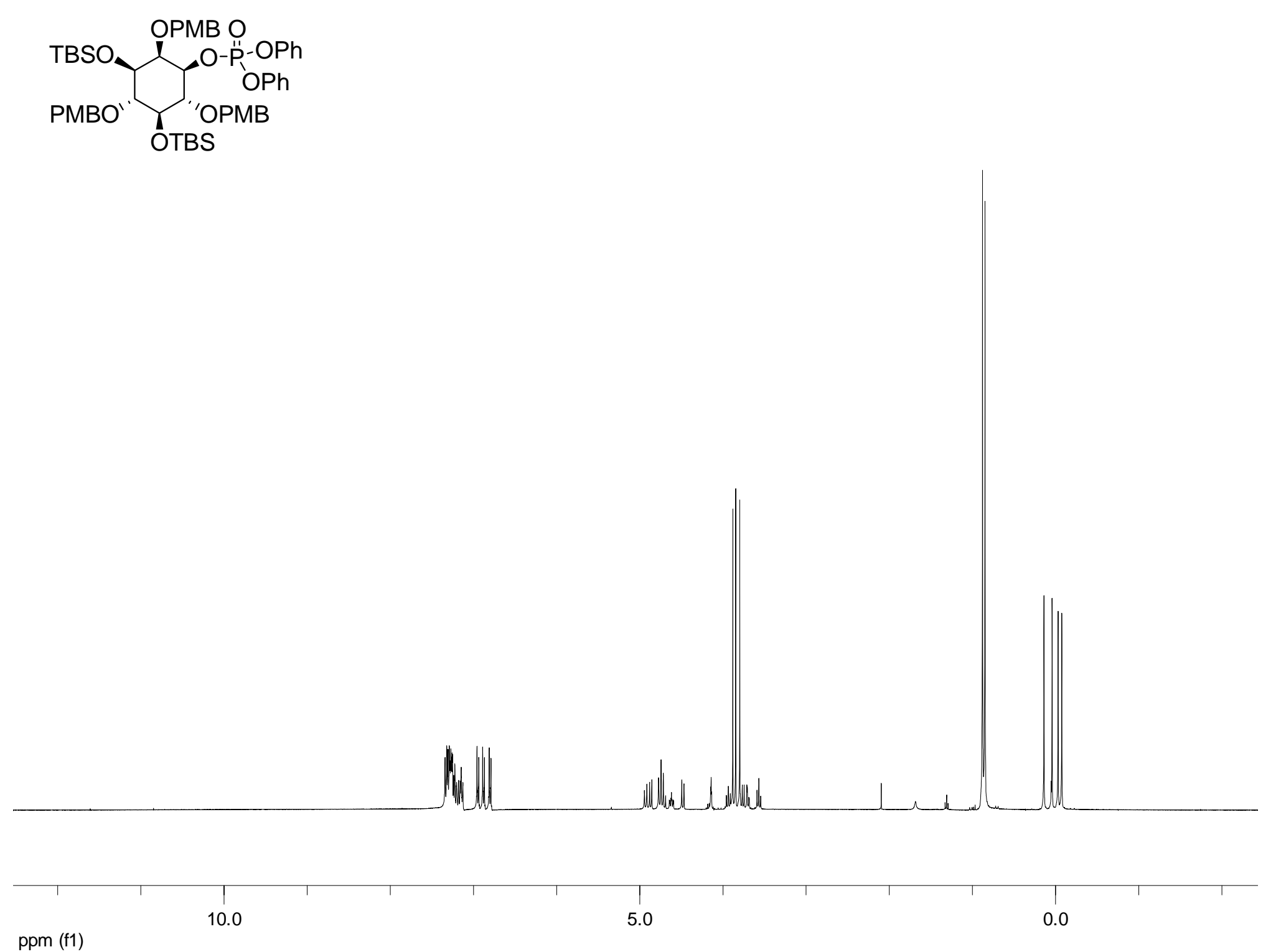

SI- 30 

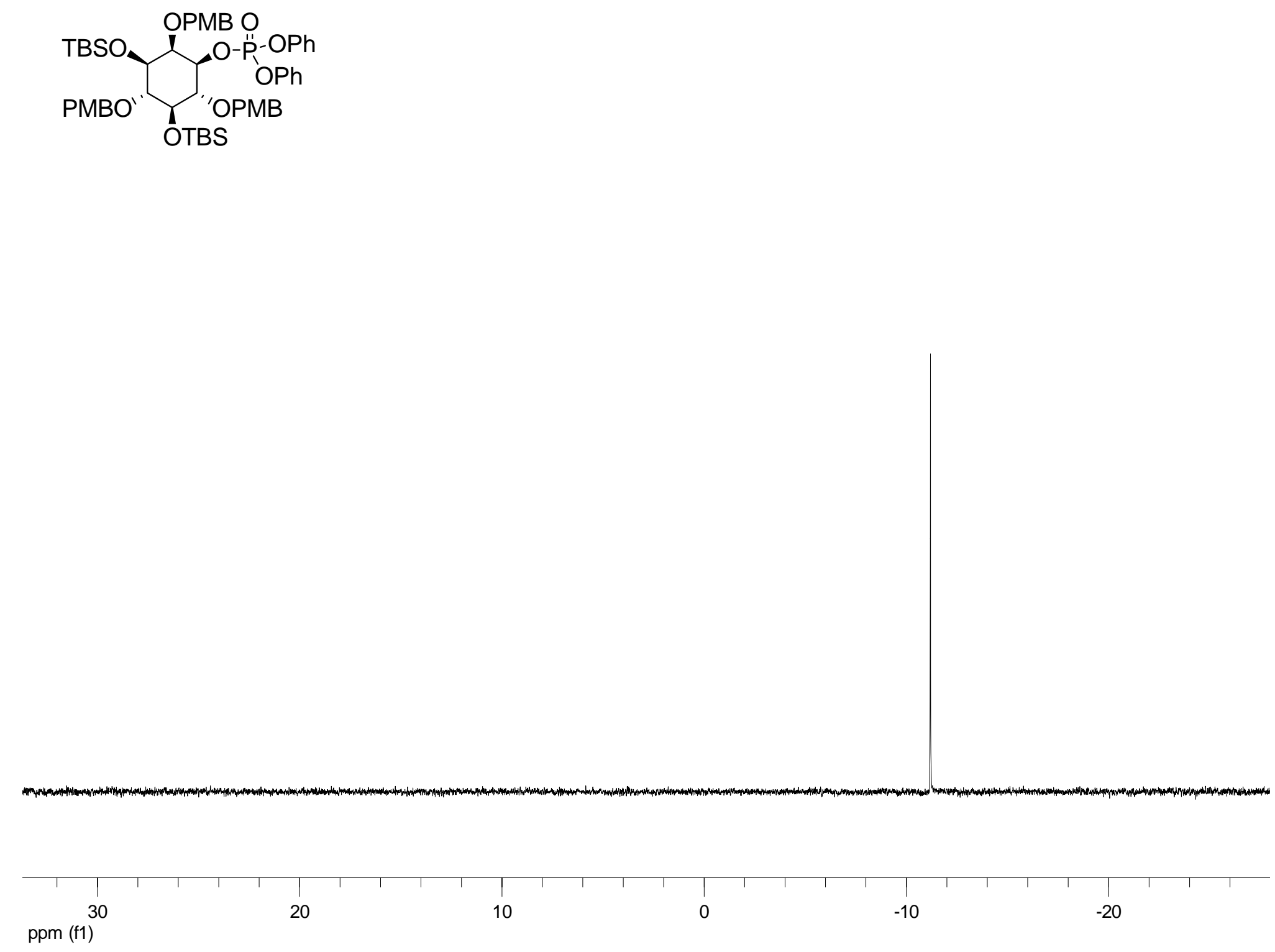

SI- 31 

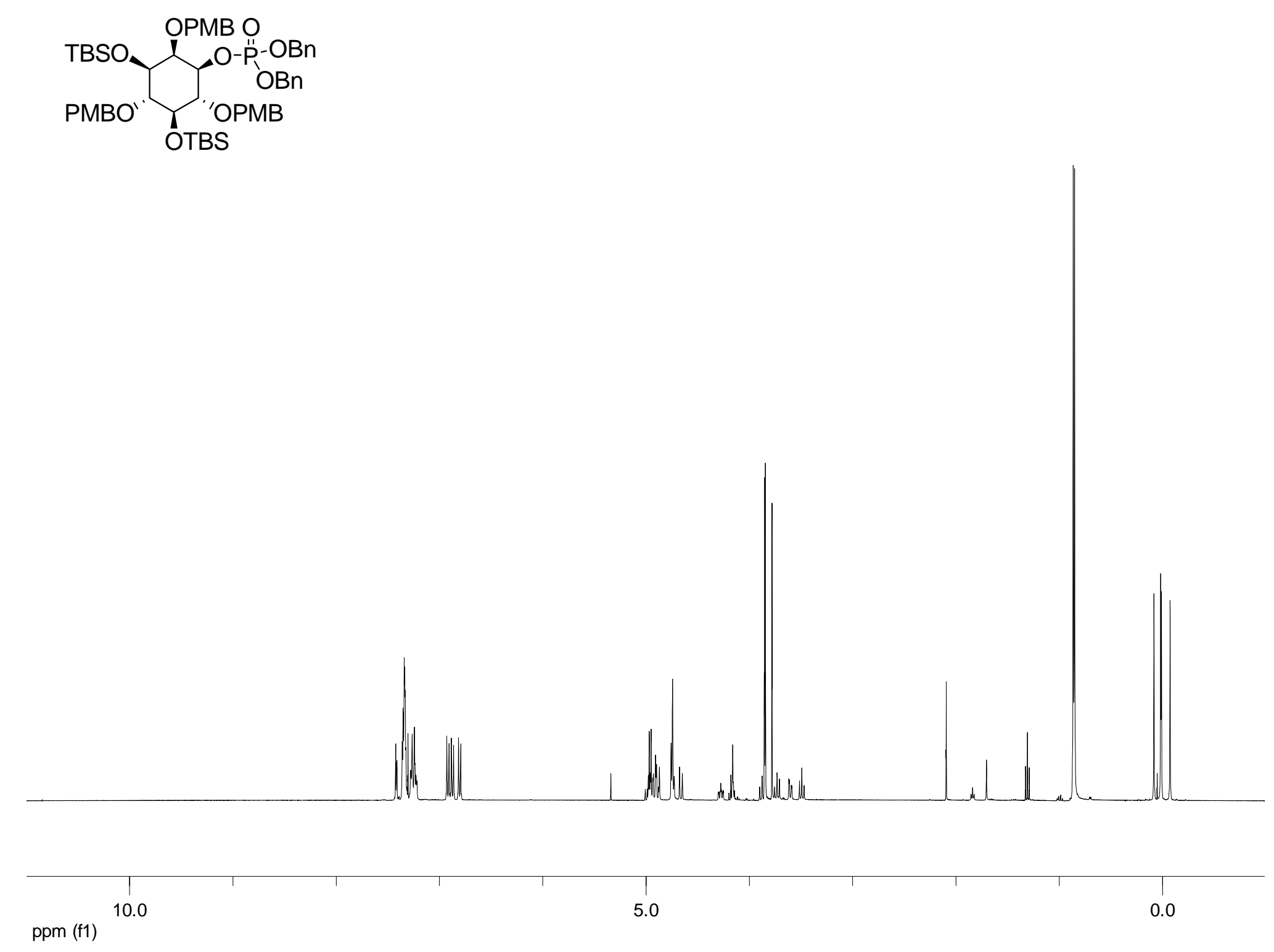

SI- 32 

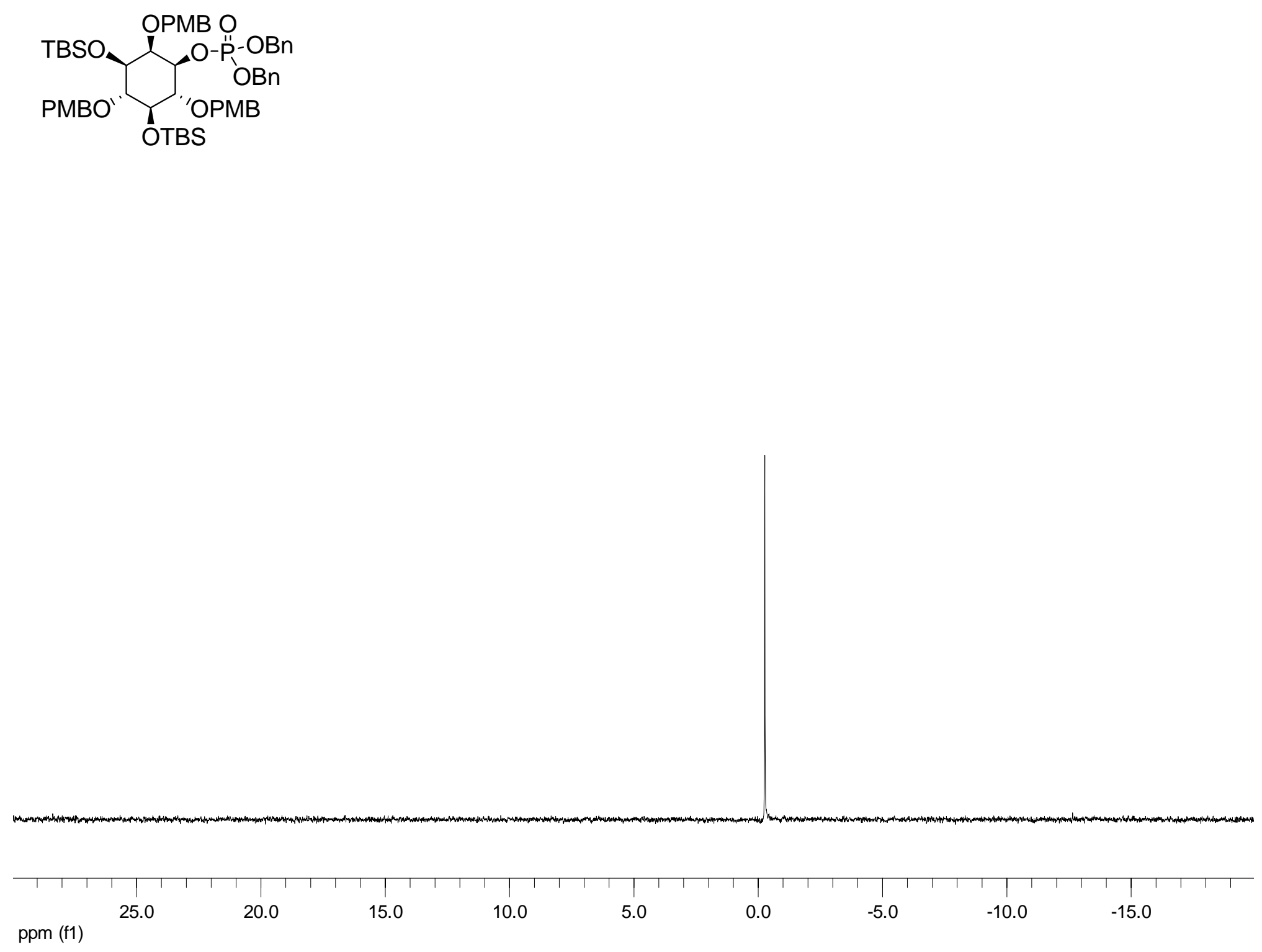

SI- 33 

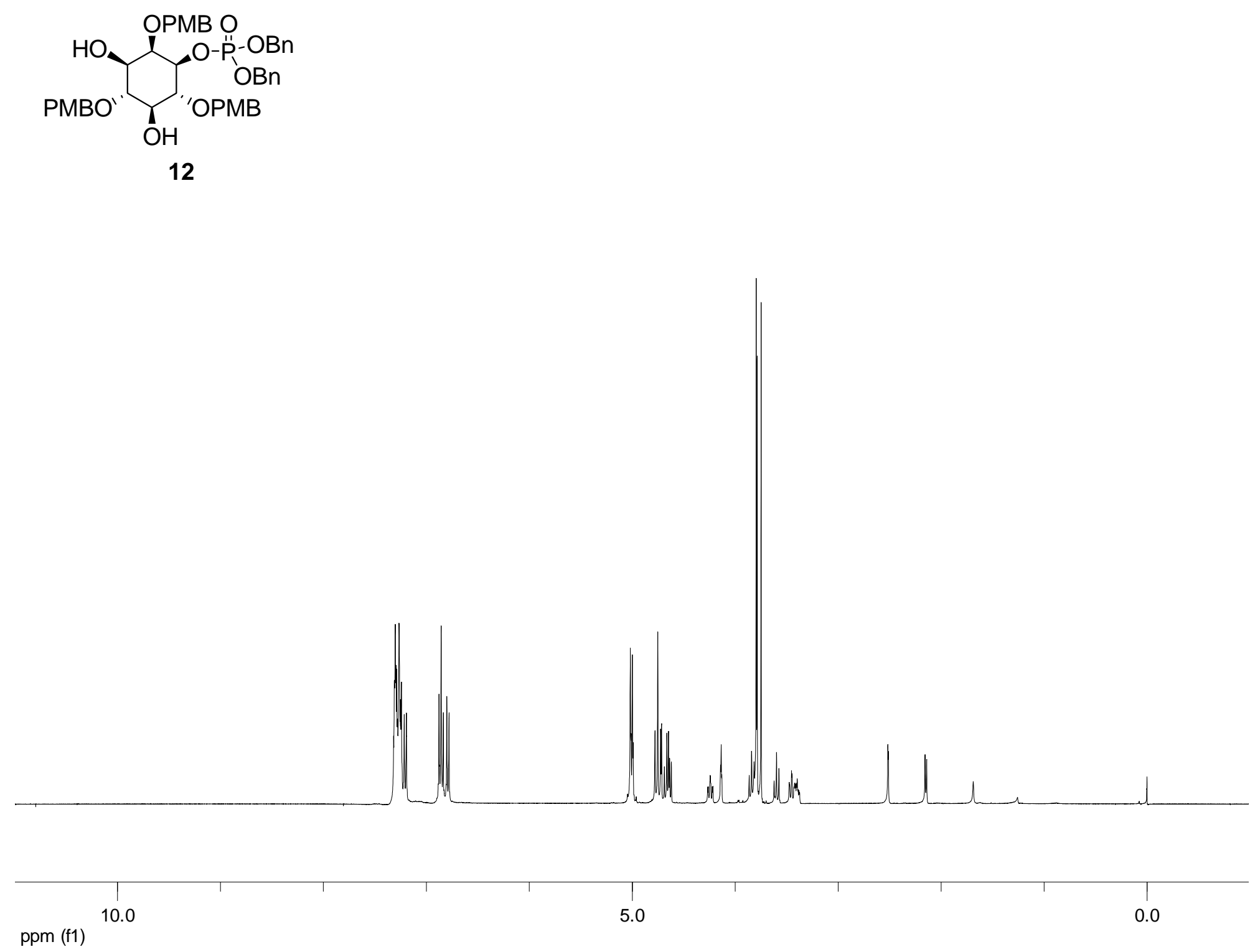

SI- 34 


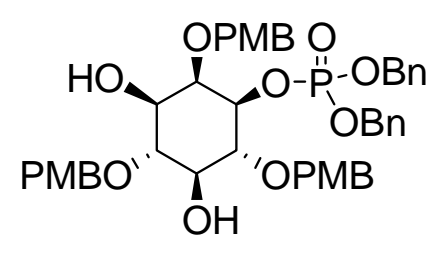

12

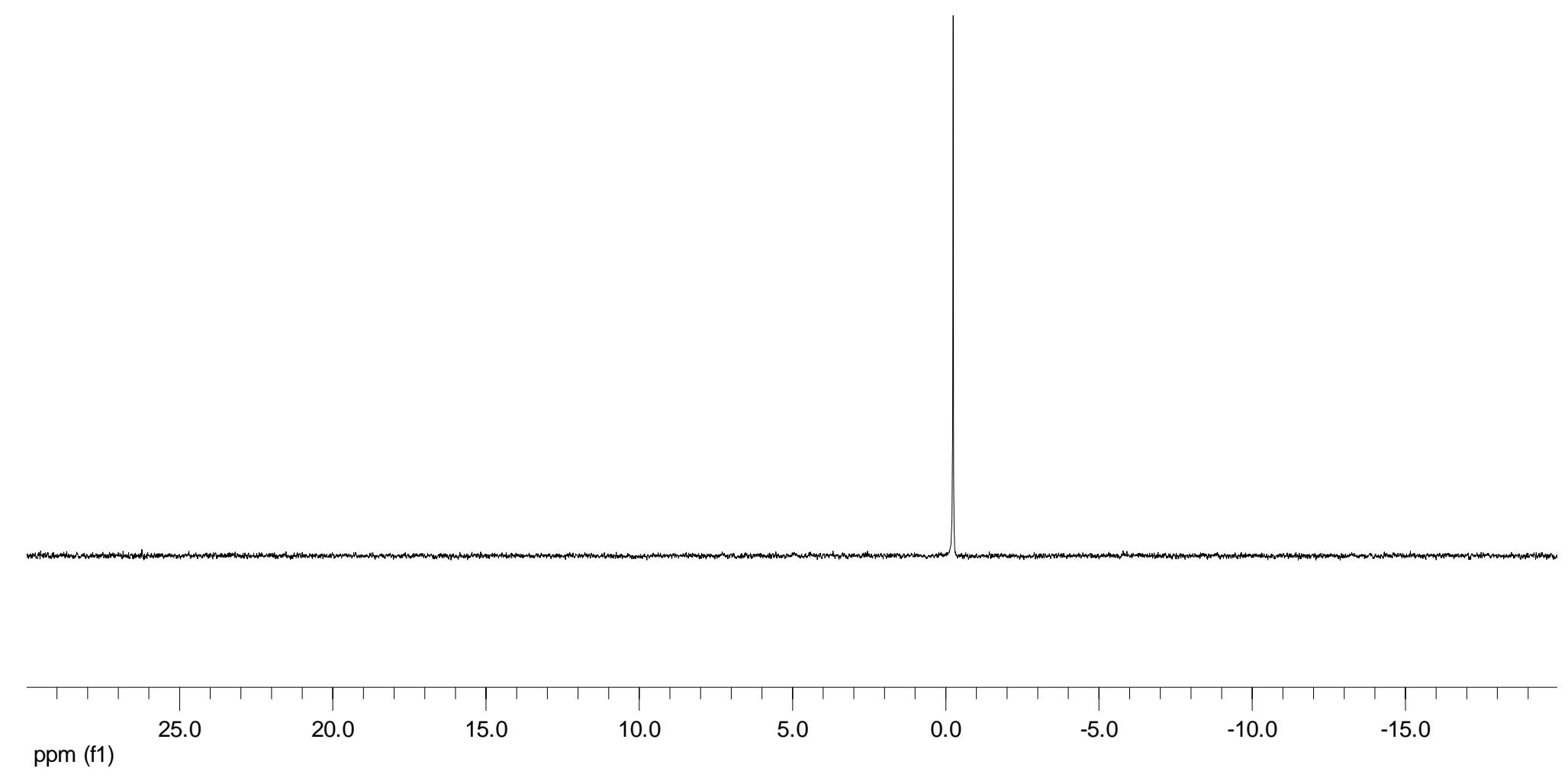

SI- 35 


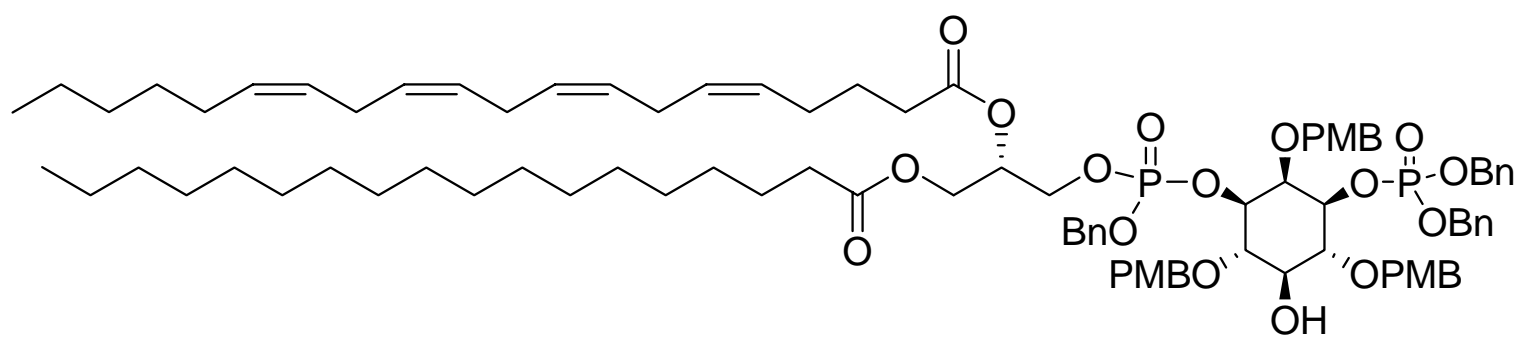

14

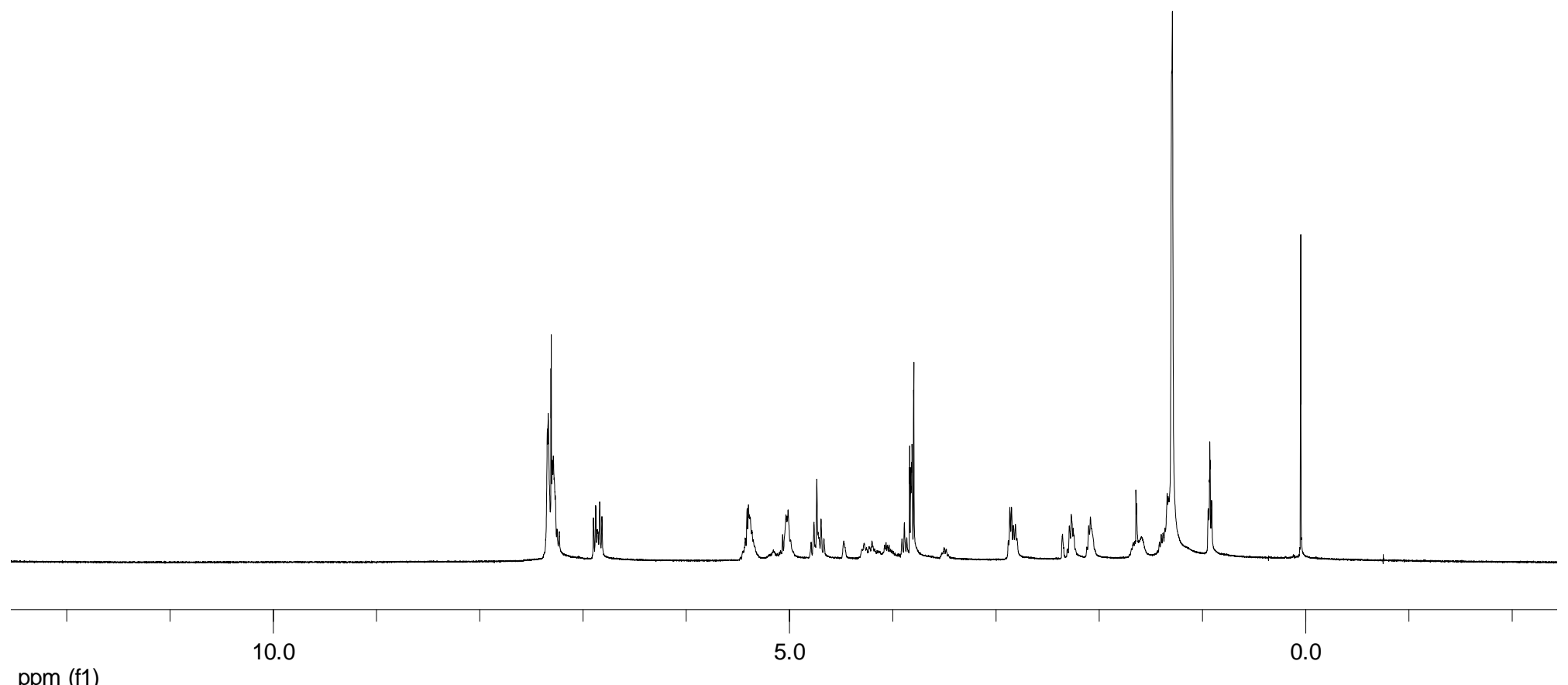

SI- 36 


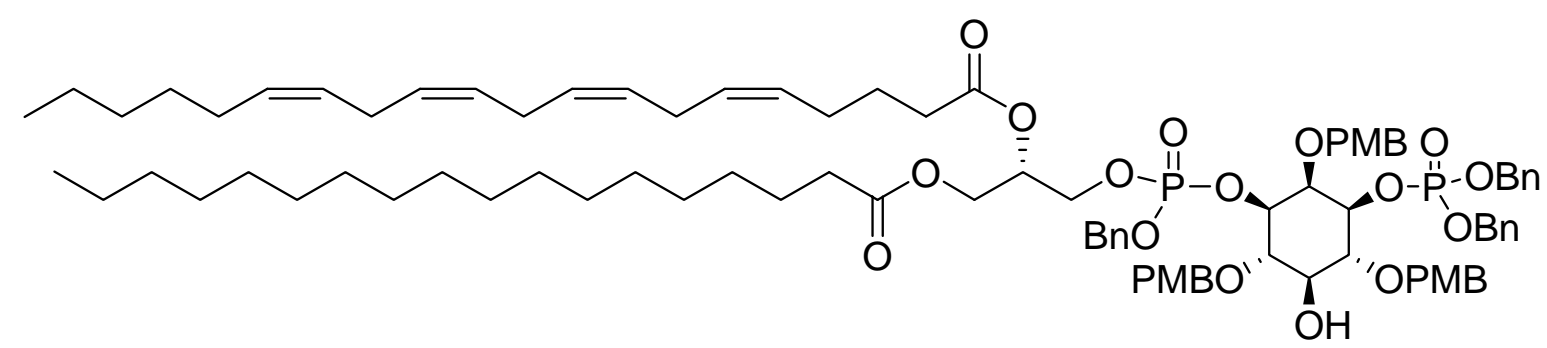

14

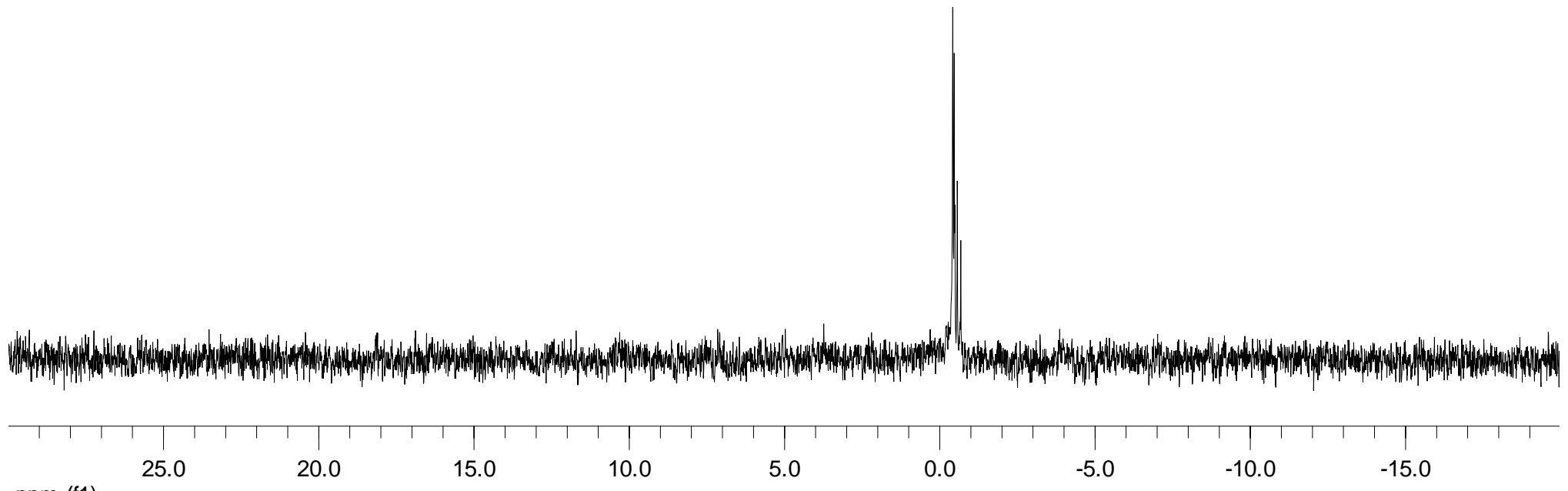

ppm (f1) 


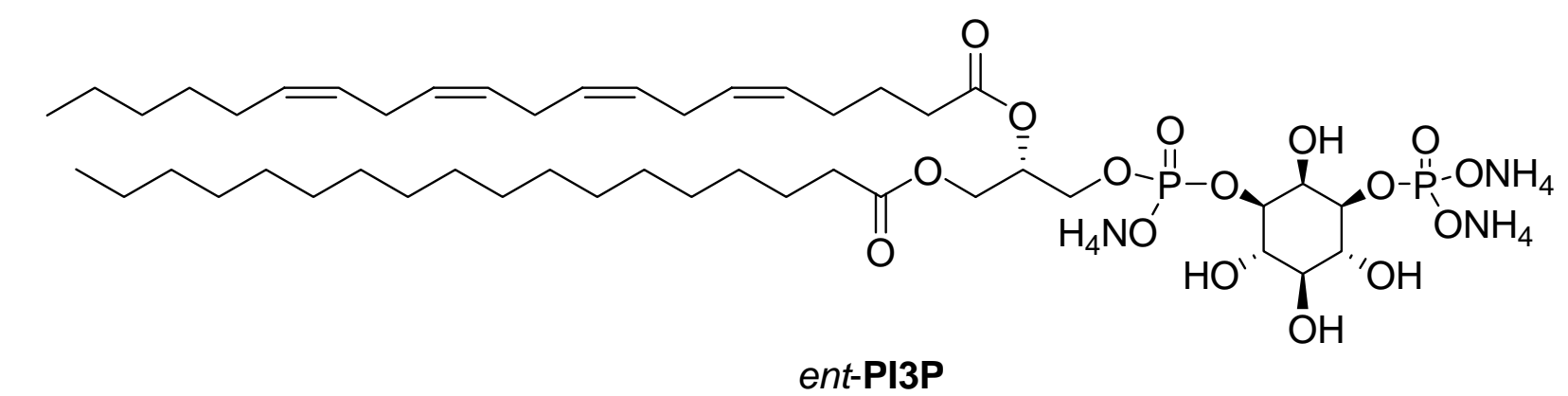

ent-PI3P 


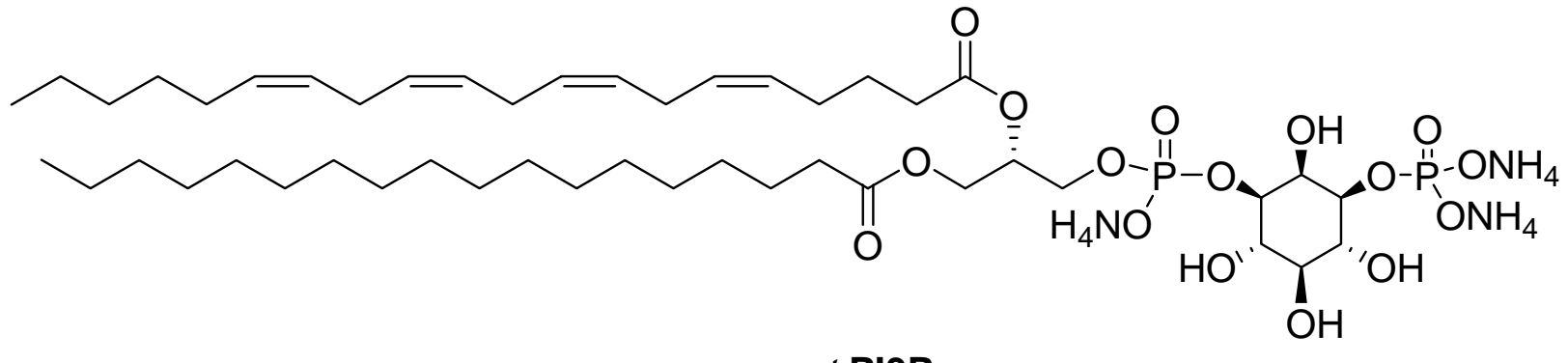

ent-PI3P

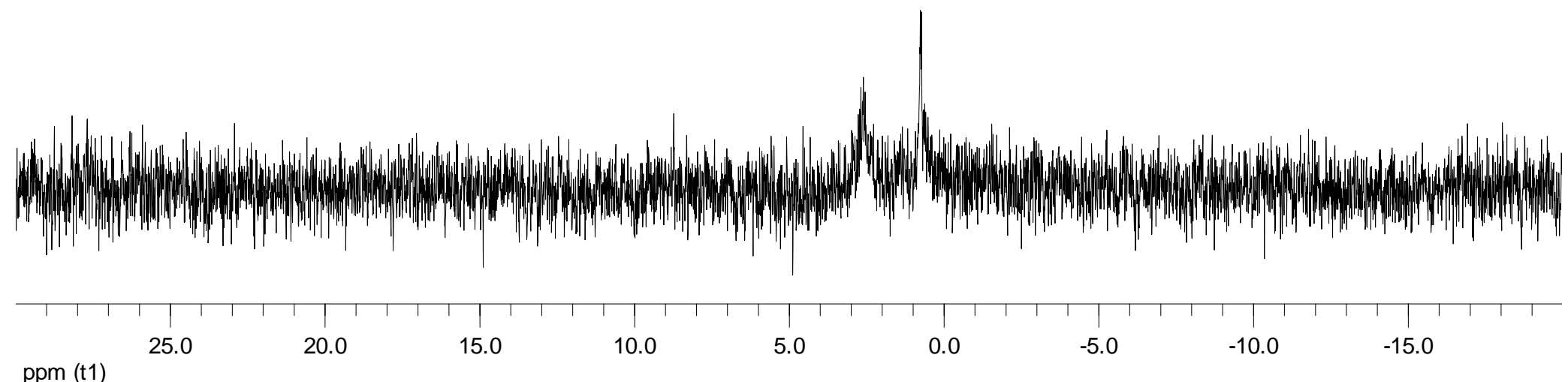

SI- 39 

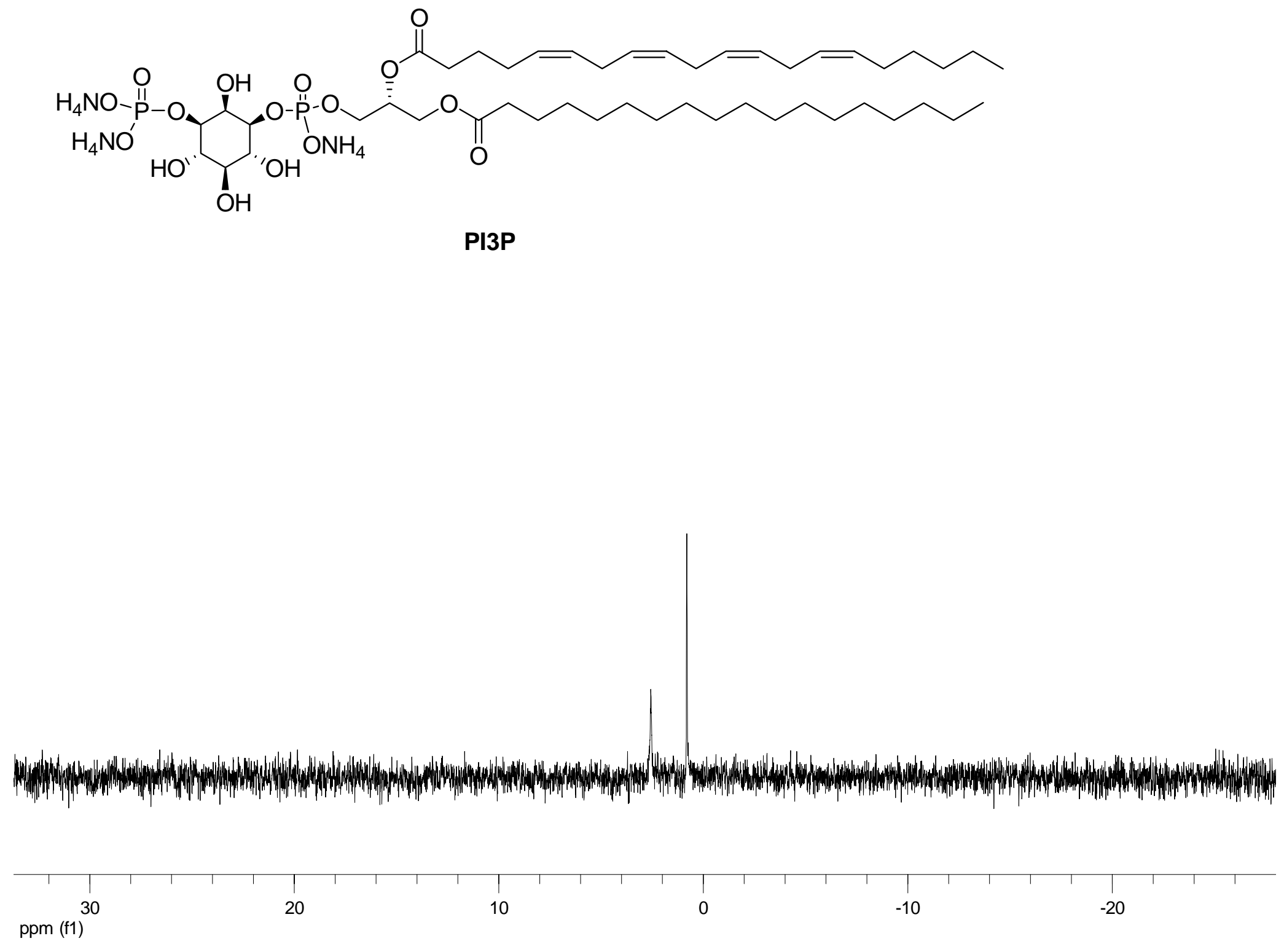

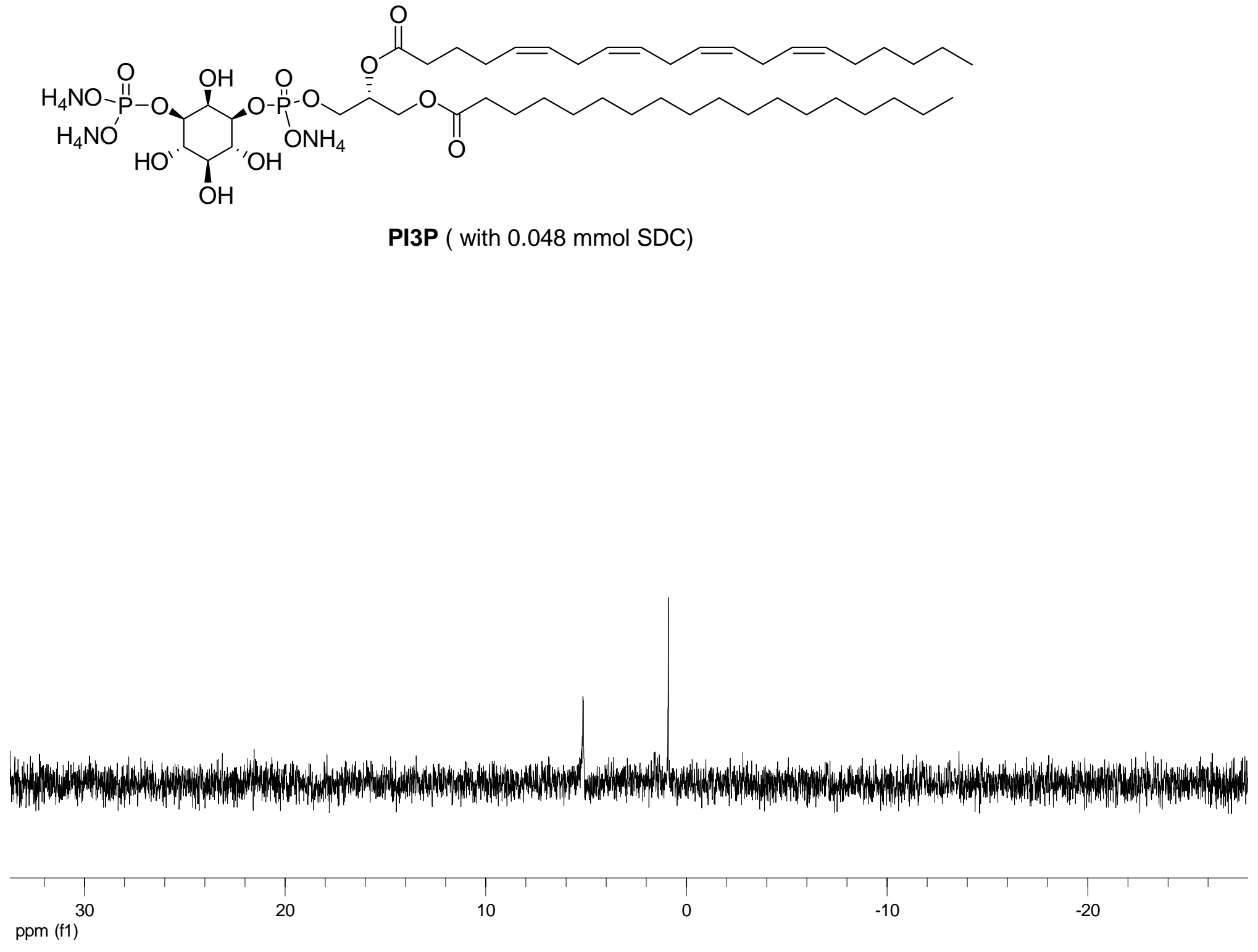